\title{
Refractory black carbon mass concentrations in snow and ice: method evaluation and inter-comparison with elemental carbon measurement
}

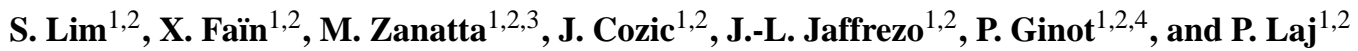 \\ ${ }^{1}$ Univ. Grenoble Alpes, Laboratoire de Glaciologie et Géophysique de l'Environnement (LGGE), 38000 Grenoble, France \\ ${ }^{2}$ CNRS, LGGE, 38000 Grenoble, France \\ ${ }^{3}$ Laboratory of Atmospheric Chemistry, Paul Scherrer Institute, 5232 Villigen PSI, Switzerland \\ ${ }^{4}$ IRD, Observatoire de Science de l'Univers de Grenoble (OSUG), 38000 Grenoble, France
}

Correspondence to: S. Lim (slim@lgge.obs.ujf-grenoble.fr)

Received: 23 January 2014 - Published in Atmos. Meas. Tech. Discuss.: 7 April 2014

Revised: 12 August 2014 - Accepted: 12 August 2014 - Published: 7 October 2014

\begin{abstract}
Accurate measurement of black carbon (BC) mass concentrations in snow and ice is crucial for the assessment of climatic impacts. However, it is difficult to compare methods used to assess BC levels in the literature as they are not the same. The single particle soot photometer (SP2) method appears to be one of the most suitable to measure low concentrations of $\mathrm{BC}$ in snow and ice. In this paper, we evaluated a method for the quantification of refractory BC $(\mathrm{rBC})$ in snow and ice samples coupling the SP2 with the APEX-Q nebulizer. The paper reviews all the steps of $\mathrm{rBC}$ determination, including SP2 calibration, correction for $\mathrm{BBC}$ particle aerosolization efficiency ( $75 \pm 7 \%$ using the APEX-Q nebulizer), and treatment of the samples. In addition, we compare the SP2 method and the thermal-optical method - Sunset organic carbon (OC) / elemental carbon (EC) aerosol analyzer with EUSAAR2 protocol - using snow and firn samples with different characteristics from the Greenland Summit, the French Alps, the Caucasus, and the Himalayas. Careful investigation was undertaken of analytical artifacts that potentially affect both methods. The SP2-based rBC quantification may be underestimated when the SP2 detection range does not cover correctly the existing size distribution of the sample. Thermal-optical EC measurements can be underestimated by low filtration efficiency of quartz fiber filter before analysis or dust properties (concentration and type), and overestimated by pyrolyzed OC artifacts during EC analysis. These results underline the need for careful assessment of the analytical technique and procedure for correct data interpretation.
\end{abstract}

\section{Introduction}

Black carbon (BC) only enters the atmosphere as a primary emission and mainly originates from incomplete combustion of biomass and fossil fuels. BC is the subject of increasing attention as it strongly absorbs visible light and thereby affects the earth's radiative budget (Bond et al., 2013; Jacobson, 2001). BC particles are ubiquitous in the atmosphere. Their relatively long residence time in the atmosphere (up to 10 days; Bond et al., 2013, and references therein) allows for efficient transport over long distances once emitted above the boundary layer, as, for example, at high-altitude or high-latitude sites in the Northern Hemisphere, where they are deposited with snow precipitation and on the surface of the snow. The deposited BC darkens the surface of the snow and ice and can modify the local radiative balance with potentially larger scale consequences for climate (Doherty et al., 2010; Flanner et al., 2007; Painter et al., 2013). The absolute rate of snow albedo reduction by $B C$ and other absorbing particles is not particularly high, but it is of concern because even slight changes in solar absorption can accelerate snowmelt (Clarke and Noone, 1985; Hansen and Nazarenko, 2004; Warren, 1984). Hence, BC deposited on snow surfaces has been identified as a significant contributing factor that may increase snowmelt over the Himalaya and the Tibetan Plateau (Flanner et al., 2007; Ginot et al., 2014; Xu et al., 2009), although the exact impact has not yet been precisely quantified. The $\mathrm{BC}$ deposited in snow is also an important indicator in ice-core studies (e.g., McConnell 
et al., 2007) as it provides information on the variability of combustion processes due to both natural and anthropogenic activities. Since multi-year observations of atmospheric BC concentrations are rare, long-term $\mathrm{BC}$ trends derived from ice-core studies are extremely useful in identifying possible changes in its sources of emissions.

The term "black carbon" is often used without a clear definition of its meaning (Petzold et al., 2013). It is now generally agreed that, when determined by thermal-optical methods using its chemical composition and carbon content, BC should be called "elemental carbon" (EC). Thermal methods have been widely used to quantify EC mass concentrations in snow and ice in the Arctic (Aamaas et al., 2011; Hagler et al., 2007), the European Alps (Legrand et al., 2007; Thevenon et al., 2009), and the Himalayas (Ming et al., 2008, 2009), as well as in the atmosphere, and the EC values obtained using these methods have been termed "BC" in many studies. Optical methods are also widely used for monitoring ambient $\mathrm{BC}$. $\mathrm{BC}$ measured using optical methods should be called "equivalent BC" (eBC) since its mass concentration is indirectly determined by applying a mass absorption cross-section (MAC) of BC (Petzold et al., 2013). A few measurements have been performed on Arctic and European Alpine ice-core samples with such optical methods (Doherty et al., 2010; Lavanchy et al., 1999). Recently, an incandescence method using a singleparticle soot photometer (SP2, Droplet Measurement Technologies, Boulder, Colorado) was used to measure refractory $\mathrm{BC}(\mathrm{rBC})$ in ice cores (Bisiaux et al., 2012a, b; Kaspari et al., 2011; Jenkins et al., 2013; McConnell et al., 2007; Sterle et al., 2013). This technique is nearly independent of the morphology of BC and of the presence of other materials, such as light-absorbing organics. Its high sensitivity, compared to other techniques, makes it particularly suitable for measurements in snow and ice-core samples from remote areas where $\mathrm{BC}$ concentrations are often low and the volume of the sample is limited. However, the use of the SP2 technique for rBC measurements in snow and ice is not currently performed in the same way in the different studies and still raises many questions, ranging from the definition of calibration material to the process of aerosolization of $\mathrm{rBC}$ particles in melted snow and ice (Schwarz et al., 2012). Appropriate treatment of the samples is also required for accurate $\mathrm{rBC}$ analysis to minimize potential losses of rBC particles. Such losses occur as $\mathrm{rBC}$ particles easily adhere to the walls of the container due to their hydrophobic nature, and tend to form agglomerations with each other and/or with other particles including dust (Schwarz et al., 2012; Wang et al., 2012).

Many laboratory studies have reported that results of measurements of environmental carbonaceous particles depend not only on their source, the combustion process and mixing state, but also on the analytical techniques and experimental procedures used (Countess, 1990; Schmid et al., 2001). A recent review by Lack et al. (2014) describes the current state of BC measurement instrumentation, including the limitations and uncertainties of available techniques. In the past decade, several inter-laboratory studies reported that method inter-comparison can yield ambient EC estimates that differ by up to 1 order of magnitude (Ten Brink et al., 2004; Schmid et al., 2001; Viana et al., 2007).

These differences appear despite good precision of individual laboratory analyses and are mainly attributed to organics that pyrolize during thermal analysis (Chow et al., 2001; Schmid et al., 2001; Cavalli et al., 2010). The ambient eBC, provided by optical measurements, can only be compared with EC (e.g., within a factor of 2 or less) when proper MAC values are used, and the values depend on the physical-chemical characteristics of the BC particles (Chow et al., 2009; Laborde et al., 2012b). Otherwise, eBC/EC ratios can easily vary by more than a factor of 3 (Jeong et al., 2004). The main factors responsible for the high variability of eBC / EC ratios are the amount of organics (e.g., refractory or water-soluble organic carbon) and dust, as well as the relative humidity of sampled air (Jeong et al., 2004; Yang et al., 2006). BC yields from the SP2 and several optical instruments were compared by Slowik et al. (2007) using laboratory-generated airbone $\mathrm{BC}$ particles. The measurements provided by the optical methods were $\sim 65 \%$ higher depending on particle morphology and coating materials, whereas the SP2 output was independent of these particle characteristics. Another recent finding reported a small positive offset associated with dust content for the SP2 measurement, but which was much smaller than the positive artifact of the optical measurement (Schwarz et al., 2012). An inter-comparison study between an SP2 and a filter-based absorption photometer continuous soot monitoring system (COSMOS, using a heated inlet) revealed the good agreement within $10 \%$ on average from measured BC concentrations in Tokyo (Kondo et al., 2011). Recently, another intercomparison study between a thermal-optical method, an optical method, and an SP2-based analysis using a standard BC aerosol (airborne combustion aerosol standard, CAST soot, whose mass size distribution was within the detection range of the SP2) showed that measured $\mathrm{rBC}, \mathrm{EC}$, and estimated eBC mass concentrations were comparable at $\sim 10 \%$ (Laborde et al., 2012b). However, the detailed parameters involved in the determination of $\mathrm{BC}$ particles in those analyses are still not fully understood. This should encourage further inter-comparison exercises. Such studies are even scarcer for snow or ice analyses. Only one inter-comparison study by Schwarz et al. (2012) between SP2 measurements and an optical method used snow sampled in semi-rural and rural areas. Given that rural and alpine aerosol samples exhibit even higher variances than urban aerosol samples in EC concentrations between analytical methods and laboratories, it is crucial to examine similarity and difference in BC particles in a variety of snow and ice samples according to different analytical methods. Furthermore, SP2 measurements and thermal-optical methods used to qualify $\mathrm{rBC}$ or EC in snow and ice have never been carefully compared, despite the observed discrepancy between $\mathrm{rBC}$ and EC concentrations even 
at the same Himalayan glacier site (e.g., Kaspari et al., 2011; Ming et al., 2008). The different terminology used in the different studies also contributes to some confusion and makes the comparison of studies somewhat difficult (Petzold et al., 2013).

In this paper, we describe and evaluate a methodology for rBC measurements in snow and firn samples using an SP2 technique that includes calibrating the SP2 with the most appropriate BC standard, building the coupling of nebulizer and SP2, and evaluating snow-sample treatment methods. We compared the results of using this method with results using a thermal-optical method, Sunset OC / EC aerosol analyzer with the EUSAAR2 (European Supersites for Atmospheric Aerosol Research) protocol of Cavalli et al. (2010) using snow and firn samples from different locations.

\section{Experimental}

\subsection{Single particle soot photometer}

\subsubsection{Principle of the SP2}

The SP2 uses a laser-induced incandescence method to measure the mass of individual rBC particles (Schwarz et al., 2006; Stephens et al., 2003) independently of particle morphology or of light scattering coating materials (Cross et al., 2010; Moteki and Kondo, 2010; Slowik et al., 2007). Individual $\mathrm{rBC}$ particles pass through the intra-cavity laser beam of a $1064 \mathrm{~nm}$ Nd YAG laser. The rBC particle absorbs light, reaches its vaporization temperature $(\sim 3700$ to $4300 \mathrm{~K}$ ) and incandesces. The mass of individual rBC particle is proportional to its incandescence signal, as detected by two photomultiplier tube (PMT) detectors with broadband and narrowband detection capabilities, respectively. The particle diameter is determined as a mass-equivalent diameter (MED) by assuming spherical morphology and an $\mathrm{rBC}$ particle density of $1.8 \mathrm{~g} \mathrm{~cm}^{-3}$ (Moteki and Kondo, 2010). In addition, an avalanche photodiode measures number concentrations and optical sizes $(\sim 100-400 \mathrm{~nm})$ of the laser light scattered by individual particles. In our case, SP2 data were processed with the SP2 measurement toolkit developed by M. Gysel at the Paul Scherrer Institute (PSI, Switzerland; http://aerosolsoftware.web.psi.ch/).

\subsubsection{Calibration of the SP2}

The SP2 was calibrated by analyzing mass-selected fullerene soot (Alfa Aesar Inc., USA). Recent studies reported the similarity between the physical properties of fullerene soot and ambient $\mathrm{rBC}$ for urban areas in Switzerland and Tokyo (Laborde et al., 2012a; Moteki and Kondo, 2010). The sizes of fullerene soot were selected by their electrical mobility diameter $\left(D_{\mathrm{mob}}\right)$ before entering the SP2 inlet by a differential mobility analyzer (DMA). The mass of mono-dispersed particles was empirically calculated using the relationship between the measured mobility diameter and the effective density of standard materials (Gysel et al., 2011; Moteki and Kondo, 2010). SP2 counts were validated by parallel measurements with a condensation particle counter (CPC). The number of concentrations obtained with both instruments agreed within $10 \%$ in the calibration range.

Fullerene soot with an $\mathrm{rBC}$ mass ranging from $\sim 0.2$ to $70 \mathrm{fg}$, corresponding to $\sim 60$ to $420 \mathrm{~nm}$ MED, was used for calibration of the SP2. The lower and upper limit of measurements for real $\mathrm{rBC}$ mass in actual samples was therefore $\sim 60-620 \mathrm{~nm}$ MED by extrapolating the data with a spline fit. The calibration size range generally covers $\sim 80-90 \%$ of observed $\mathrm{rBC}$ mass in the SP2 detection range for the snow and firn samples tested (Sect. 2.4). Particles heavier than $\sim 220 \mathrm{fg}$ (corresponding to $\sim 620 \mathrm{~nm}$ MED in rBC diameter) were detected by the SP2 but treated as if they had a BC mass of $\sim 220 \mathrm{fg}$ due to the saturation of the A/D converters of the detectors. Note that the value $220 \mathrm{fg}$ corresponds to a fullerene calibration, and the determined $\mathrm{rBC}$ mass and size at this saturation point might differ slightly depending on the calibration materials/curves. For ease of reading, data collected at this saturation point are not presented in figures.

Calibration was performed regularly, specifically when the SP2 was moved, and calibration curves (for the high-gain output of the broadband incandescence channel) are reproducible within $4.5 \%$ for fullerene soot. We used signals from the broadband detector for $\mathrm{rBC}$ particle detection, as it showed less noise and more stable calibration curves than the narrowband detector.

\subsection{SP2 and nebulizer coupling for snow and ice samples}

Coupled to a nebulizer, the SP2 can be used to measure rBC mass concentration in liquid-phase samples. Different types of nebulizing techniques have been used for ice-core analysis. The SP2 has been coupled to an ultrasonic nebulizer (U5000AT, CETAC Technologies, Omaha, NE, USA) for rBC measurements of ice cores from Greenland (McConnell et al., 2007), Himalaya (Kaspari et al., 2011), and Antarctica (Bisiaux et al., 2012a, b), and for analysis of rain water (Ohata et al., 2011, 2013). Similarly to Wendl et al. (2014), we introduce a jet nebulizer (APEX-Q, Elemental Scientific Inc., Omaha, NE, USA) to aerosolize the aqueous samples for SP2 analysis. This section describes the coupling between SP2 and APEX-Q, as well as a comparison between APEX$\mathrm{Q}$ and U5000AT nebulizers.

\subsubsection{Nebulizer configurations}

Self-aspiration by a flow of compressed air of $1 \mathrm{~L} \mathrm{~min}^{-1}$ introduces the liquid sample in the APEX-Q nebulizer. Water droplets are then formed by the difference in pressure through a capillary of a concentric glass nebulizer. Particles are spun in the heated cyclonic spray chamber and liquid 
is desolvated in several heating $\left(140^{\circ} \mathrm{C}\right)$ and cooling $\left(2{ }^{\circ} \mathrm{C}\right)$ steps, finally producing aerosols. The details of the U5000AT geometry and performance are described in previous studies (e.g., Ohata et al., 2011; Zanatta, 2012). The liquid sample flow rate is $70 \pm 10 \mu \mathrm{L} \mathrm{min}^{-1}$ for the APEX-Q, and the sample at $1.1 \mathrm{~mL} \mathrm{~min}^{-1}$ is delivered by a peristaltic pump for the U5000AT nebulizer, operated with a compressed air flow of $0.5 \mathrm{~L} \mathrm{~min}^{-1}$. In this study, compressed air flows required for operation of both APEX-Q and U5000AT nebulizers were regulated using mass flow controllers. Liquid flow was monitored by a liquid mass flow meter (ASL 1600 series, Sensirion, Switzerland) for APEX-Q, and calculated using the peristaltic pump speed for U5000AT.

\subsubsection{BC standard solutions}

We used AQ (Aquadag ${ }^{\circledR}$, Acheson Inc., USA), an aqueousbased colloidal dispersion of ultra-fine graphite, to prepare rBC standard solutions. AQ solid content provided by the manufacturer is $22 \%$, but it slowly dries out. The solid content of our AQ increased to $28 \%$ after being used over 2 years.

The BC content of AQ was evaluated with the Sunset OC / EC analyzer (Sect. 2.3). $10 \mu \mathrm{g}$ (dry mass) of AQ were dissolved in $50 \mu \mathrm{L}$ ultrapure water and loaded on quartz fiber filters $\left(1.5 \mathrm{~cm}^{2}, n=7\right)$. We did not actively pump through the filters to avoid rBC losses by water penetration. Analysis of these filters using the Sunset instrument indicated that EC makes up $\sim 87 \%$ of the total mass of $A Q$, and this value was later used when preparing AQ standard solutions for SP2 external calibration (see Sect. 2.2.4). In contrast, $100 \%$ of gravimetric mass of fullerene soot was measured as EC. Our estimate of $\mathrm{rBC}$ content of dry AQ is slightly above $\sim 71$ and $76 \%$, the values reported by Gysel et al. (2011) and Wendl et al. (2014), respectively. How the thermal-optical analyzer is programmed can introduce some variability in the evaluation of $\mathrm{rBC}$ content of dry AQ. However, dry $\mathrm{rBC}$ contents of an AQ batch can vary, and we therefore suggest that each batch needs to be individually characterized.

For nebulizer efficiency tests and calibrations (Sects. 2.2.3 and 2.2.4), an AQ rBC stock solution, with a concentration of $\sim 10000 \mu \mathrm{g} \mathrm{L}{ }^{-1}$, was prepared in a $50 \mathrm{~mL}$ polypropylene (PP) tube. This stock solution $\left(10000 \mu \mathrm{g} \mathrm{L}^{-1}\right)$ was then diluted to 100 and $50 \mu \mathrm{g} \mathrm{L}^{-1}$. The $50 \mu \mathrm{g} \mathrm{L}^{-1}$ AQ solution was diluted again to prepare low concentration standard solutions $\left(25,10,5,1,0.5,0.1 \mu \mathrm{g} \mathrm{L}^{-1}\right)$. AQ solutions were always sonicated $15 \mathrm{~min}$ before dilution.

\subsubsection{Size-dependence of the aerosolization efficiency}

We used mono-dispersed polystyrene latex (PSL) spheres with diameters of 150, 200, 240,350, and $600 \mathrm{~nm}(3000 \mathrm{se}-$ ries nanosphere, Thermo scientific, USA) to specifically investigate size dependence of the aerosolization efficiency for the APEX-Q nebulizer. Dilutions allowed to adjust particle numbers of PSL solutions to levels similar to those observed for $\mathrm{rBC}$ samples of concentrations ranging from 10 to $100 \mu \mathrm{g} \mathrm{L}^{-1}$. The number concentrations of the PSL solutions reported by the manufacturer were used to estimate the original number concentrations of the PSL solutions before entering the APEX-Q, and the aerosolized particle number concentrations of the diluted PSL solutions were measured by the SP2. For these SP2 measurements, we used the specific channel for detection of scattering particles. A size-independent aerosolization efficiency of $72 \pm 5 \%$ was determined for the APEX-Q nebulizer for PSL sizes ranging from 150 to $600 \mathrm{~nm}$ (Fig. S1 in the Supplement). This result is consistent with the study of Wendl et al. (2014), which reports a size-independent aerosolization of over a $100-1000 \mathrm{~nm}$ range for the APEX-Q.

Our PSL-based results suggest that the APEX-Q/SP2 system preserves the $\mathrm{rBC}$ size information when measuring liquid samples. Contrarily, previous studies reported sizedependent aerosolization capability for the U5000AT nebulizer (Ohata et al., 2013; Schwarz et al., 2012; Wendl et al., 2014). The efficiency of the U5000AT for aerosolizing PSLs was observed to suddenly drop at $500 \mathrm{~nm}$ (Ohata et al., 2013; Schwarz et al., 2012) or gradually decrease from $200 \mathrm{~nm}$ toward larger sizes (Wendl et al., 2014).We did not characterize the U5000AT nebulizer with PSLs in this study, but we observed a larger $\mathrm{rBC}$ mass-median diameter (MMD) for the liquid removed during first drainage of the U5000AT when compared to the original sample, confirming a decrease in aerosolization efficiency for larger particles.

\subsubsection{Aerosolization efficiency determined by gravimetric rBC standard solutions}

The aerosolization efficiency of $\mathrm{rBC}$ particles through a nebulizer $\left(E F_{\text {neb }}\right)$ was derived by the following equation:

$E F_{\text {neb }}=M_{\mathrm{SP} 2} \times F_{\text {neb.gas }} /\left(m_{\text {samp }} \times F_{\text {neb.liq }}\right)$,

where $M_{\mathrm{SP} 2}$ is the $\mathrm{rBC}$ mass concentration measured by the $\mathrm{SP} 2\left(\mu \mathrm{g} \mathrm{cm}^{-3}\right), F_{\text {neb.gas }}$ is the air flow rate $\left(\mathrm{cm}^{3} \mathrm{~min}^{-1}\right)$, $m_{\text {samp }}$ is the $\mathrm{rBC}$ mass concentration of the injected sample $\left(\mu \mathrm{g} \mathrm{L}^{-1}\right)$, and $F_{\text {neb.liq }}$ is the liquid-flow rate of the sample $\left(\mathrm{L} \min ^{-1}\right)$.

The repeated blank (Milli- $\mathrm{Q}^{\circledR},>18.2 \mathrm{M} \Omega, 0.2 \mu \mathrm{m}$ filtration) tests $(N>10$ for both nebulizers) revealed for each nebulizer similar limits of detection (LOD, mean $+3 \sigma$ of blank), limits of quantification (LOQ, mean $+10 \sigma$ of blank), and coefficients of variation $(\mathrm{CV}, \sigma /$ mean $\times 100)$ of $\sim 0.01 \mu \mathrm{g} \mathrm{L}^{-1}, \sim 0.03 \mu \mathrm{g} \mathrm{L}-1$, and $\sim 70 \%$, respectively.

Evaluation of aerosolization efficiency of the APEX-Q was performed with eight gravimetric standards, AQ in aqueous phase (ranging $0.1-100 \mu \mathrm{g} \mathrm{L}^{-1}$ ) analyzed every 2 weeks. Over a 10-month period, and independently of concentrations, $75 \pm 7 \%(n=20, \mathrm{CV}=9 \%)$ of $\mathrm{rBC}$ mass was recovered. This value is in excellent agreement with the aerosolization efficiency estimated from the PSL solution 
analysis (i.e., $72 \pm 5 \%$ in Sect. 2.2.3). The fraction of AQ that was not aerosolized was partially identified in the APEX-Q drains, or adhering to the internal surface of the nebulizer (see the Supplement and Fig. S2).

The U5000AT does not demonstrate a size-independent aerosolization capability (see Sect. 2.2.3), and thus should strictly not be calibrated with polydispersed gravimetric $\mathrm{rBC}$ standards for particle losses during nebulization. However, such calibrations can improve our understanding of the behavior of the U5000AT, and have already been reported before (Bisiaux et al., 2012a, b; Jenkins et al., 2013; Kaspari et al., 2011; McConnell et al., 2007). In this study, approximately $60-70 \%$ of the sample volume injected to the U5000AT was lost during the first drainage before conversion to water droplets by the piezoelectric transducer. When the sample volume collected during the first drainage was subtracted from the sample volume injected into the nebulizer, an aerosolization efficiency of $30 \pm 3 \% \quad(n=4$, $\mathrm{CV}=8 \%$ ) was observed. Following a similar approach, Kaspari et al. (2011) reported an efficiency of $\sim 50 \%$, a higher value likely explained by a different setting of the U5000AT. However, this approach may be unrealistic as there is no evidence that $\mathrm{rBC}$ particles are homogeneously distributed in between the first drainage and the aerosols that are produced. Considering sample loss during the first drainage, $E F_{\text {neb }}$ of U5000AT of $\sim 10 \%$ was obtained, a value consistent with that reported in Ohata et al. (2011), although these authors operated the U5000AT with a slightly different setting. Figure 1 shows mass size distributions of AQ in water when nebulization was carried out with the APEX-Q and the U5000AT. Both distributions show an MMD of 210$220 \mathrm{~nm}$ MED, but lower amplitude for the U5000AT reflects low aerosolization efficiency. For both nebulizers, the shape of size distribution was independent of AQ concentrations over the $0.1-100 \mu \mathrm{g} \mathrm{L}^{-1}$ range.

In the following, we exclusively report $\mathrm{rBC}$ analysis obtained by coupling the SP2 analyzer with the APEX-Q nebulizer. Our study suggests that $\mathrm{rBC}$ losses during aerosolization depend on factors that are specific to each analytical system, underlining the crucial need for calibration. Thus, quantification of $\mathrm{rBC}$ losses during aerosolization, i.e., calibration of the APEX-Q/SP2 coupling, was performed regularly (every 2 weeks) using eight AQ standards, and daily during each analytical session using three standards. Although the results were always within the range of $75 \pm 7 \%$, we recommend such daily calibration using three standards to ensure that aerosolization efficiency remains stable and to ensure that no unlikely dysfunction may be affecting the nebulizer. The typical errors of $E F_{\text {neb }}, M_{\mathrm{SP} 2}, F_{\text {neb.gas}}$, and $F_{\text {neb.liq }}$ were estimated to be around $15,10,5$, and $10 \%$, respectively, based on their repeated measurement, resulting in the overall uncertainty of about $20 \%$.

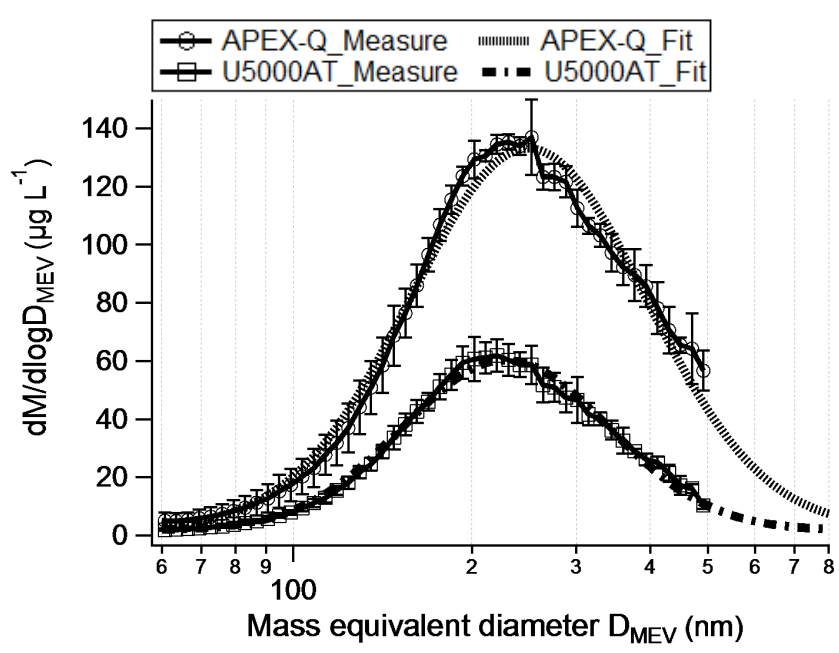

Figure 1. Mass size distributions of polydispersed AQ $\left(100 \mu \mathrm{g} \mathrm{L}^{-1}\right)$ measured with APEX-Q and U5000AT. The whiskers stand for one standard deviation. Histogram bin size is 50 .

\subsubsection{Repeatability and stability of the APEX-Q/SP2 coupling}

The repeatability and stability of $\mathrm{rBC}$ detection with our APEX-Q/SP2 system was first investigated by repeating the measurement of a single French Alpine (Col du Dôme site, hereafter "CDD", Sect. 2.4.1) snow sample ( $n=30$, one measurement every 2 minutes) over $1 \mathrm{~h}$. The total analysis time was limited to $1 \mathrm{~h}$ to avoid uncertainties driven by $\mathrm{rBC}$ losses during liquid-phase storage at room temperature (Sect. 3.1.5). rBC concentration averaged $6.3 \pm 0.3 \mu \mathrm{g} \mathrm{L}^{-1}$ over $1 \mathrm{~h}$, resulting in a $\mathrm{CV}$ of $3.9 \%$.

As presented in detail by Ohata et al. (2011), the evaporation of water droplets in the heated zone of the nebulizer can promote $\mathrm{rBC}$ particle coagulation if multiple particles have been incorporated in a single water droplet. Thus, we also investigated the dependence of size distributions on sample concentrations. The MMD and the count median diameter (CMD) of AQ obtained from lognormal fits were evaluated at different $\mathrm{rBC}$ concentrations ranging from 0.1 to $100 \mu \mathrm{g} \mathrm{L}-1$, i.e., the rBC concentrations frequently observed in snow and firn samples (see Table 2). Each measurement was made in triplicate using new standard solutions. The mean values of the MMD and the CMD were 220 and $67 \mathrm{~nm}$ MED for $\mathrm{rBC}$ concentrations ranging from 0.1 to $100 \mu \mathrm{g} \mathrm{L}^{-1}$, resulting in a $\mathrm{CV}=1.5$ and $0.6 \%$, respectively. The stability observed for MMD and CMD when measuring these AQ solutions demonstrates that $\mathrm{rBC}$ size distributions are not affected by aerosolization. This conclusion was further supported by PSL measurements. Coagulated particles (determined when the mean diameter increases by more than $20 \%$ ) represented only $1-2 \%$ of the total number of detected PSL particles of 200, 240, and $350 \mathrm{~nm}$ (see Sect. 2.2.3). Consequently, 
coagulation of $\mathrm{rBC}$ particles is likely negligible when using the APEX-Q nebulizer.

Different chemical species including ionic water-soluble species, such as sulfate and calcium, are included in solid precipitations (Preunkert et al., 2000; Savarino and Legrand, 1998) and thus coexist with rBC particles in deposited snow and ice. AQ solutions spiked with water-soluble ionic species were also analyzed to investigate potential artefacts, since water-soluble species may affect the surface tension of droplets, and hence nebulizer efficiency (Facchini et al., 2000; Ohata et al., 2011). To assess this effect in our system, we measured $\mathrm{rBC}$ concentrations of AQ solutions $\left(10 \mu \mathrm{g} \mathrm{L}^{-1}\right)$ with $100-1000 \mathrm{ppb}$ of sulfate and calcium, using five different concentrations. This range of sulfate and calcium covers the typical values in ice cores collected from the European Alpine region (Preunkert et al., 2000). The $\mathrm{rBC}$ concentrations in these artificial samples were stable within $8 \%$ and $5 \%$ without any trend for the AQ+ sulfate samples and the $\mathrm{AQ}+$ calcium samples, respectively. Using the U5000AT/SP2 system, Ohata et al. (2011) also concluded that analytical errors due to possible changes in surface tension caused by such species are negligible, however, these authors mentioned that this may not be the case for high concentrations of water-soluble, humic-like substances (HULIS), e.g., $>100 \mathrm{mg} \mathrm{L}^{-1}$. Typical water-soluble HULIS levels are below $0.05 \mathrm{mg} \mathrm{L}^{-1}$ in the French Alpine ice core over the 1920-2004 time period (Guilhermet et al., 2013). The impact of water-soluble species on rBC particle aerosolization driven by change in water-surface tension should thus be negligible.

\subsection{Thermal-optical detection of EC applied to snow and ice samples}

One of the aims of this study was to compare SP2 and thermal-optical methods (Sect. 3.2). Briefly, the thermaloptical technique used for this comparison follows the EUSAAR2 protocol (Cavalli et al., 2010).

This protocol involves an OC/EC aerosol analyzer (Sunset laboratory Inc., US) that has been widely used for EC and OC analysis. The preheated quartz fiber filter, loaded with particles, is first heated in an oxygen-free, ultra-high purity helium atmosphere in increasing temperature steps, which allows for the detection of various organic carbon fractions. Then, the gas is switched to a $2 \% \mathrm{O}_{2} / \mathrm{He}$ mixture and the filter is heated with increasing temperature steps for determination of EC. During the initial heating steps, some OC may undergo pyrolyzation (resulting in "pyrolyzed OC") and be finally determined as EC due to EC-like light absorption. This pyrolytic conversion was continuously monitored and taken into account by measuring the transmission of a laser beam.
Finally, sample decarbonation was conducted for all samples before analysis in the Sunset OC /EC aerosol analyzer. Most of the samples presented in this study were collected at sites that were potentially affected by Saharan or Asian dust. Such dust contains calcium carbonate as one of the major constituents of coarse particles (Karanasiou et al., 2011, and references therein; Maupetit and Delmas, 1994). We observed that a positive EC artifact from calcium carbonate $(\sim 6 \mu \mathrm{g})$ was efficiently removed when the chemical decarbonation procedure was applied to a filter loaded with both AQ $(10 \mu \mathrm{g})$ and calcium carbonate $(200 \mu \mathrm{g}$, a level in the range frequently observed in CDD ice cores: Preunkert et al., 2000). Further results and details about the chemical decarbonation and filtration procedure are presented in the Supplement. Filtration with $100 \mathrm{~mL}$ of ultrapure water and a decarbonation procedure led to an LOD of $4 \mu \mathrm{g} \mathrm{C}$ for OC and of $0.1 \mu \mathrm{g} \mathrm{C}$ for EC. Filtration with ultrapure water without decarbonation showed the same detection limits, indicating that this process does not induce any contamination.

\subsection{Origin of snow and ice samples used in the study}

\subsubsection{Alpine surface snow}

Alpine snow samples were collected in September 2012 from the surface and from a $1.8 \mathrm{~m}$ deep snow pit at the CDD $\left(45^{\circ} 50^{\prime} \mathrm{N}, 6^{\circ} 50^{\prime} \mathrm{E}, 4250 \mathrm{~m}\right.$ a.s.l. $)$, located close to the summit of Mont Blanc (French Alps). We collected snow samples $(n=46)$ from the top $2 \mathrm{~cm}$ snow layer across an area of $0.8 \mathrm{~m} \times 1.3 \mathrm{~m}$ and over a period of $1 \mathrm{~h}$. In addition, snow samples were collected from the top $2 \mathrm{~cm}$ layer $(n=5)$ and from the top $5 \mathrm{~cm}$ layer $(n=5)$ in a neighboring area, measuring $0.3 \mathrm{~m} \times 1.9 \mathrm{~m}$. The samples from the top $2 \mathrm{~cm}$ layer and from the top $5 \mathrm{~cm}$ layer were respectively stored in 50 and $125 \mathrm{~mL}$ PP containers pre-rinsed with ultrapure water. The water equivalent volume of each snow sample was $\sim 10$ and $30 \mathrm{~mL}$ for the 50 and $125 \mathrm{~mL}$ container, respectively. Snow was collected in one or two $1 \mathrm{~L}$ glass containers (Pyrex) from each layer of a four-layer snow pit. The snow pit was divided into layer 1 ("fresh snow"), layer 2 ("summer layer"), layer 3 ("dust deposition"), and layer 4 ("winter layer"). The collected samples were sealed in plastic bags, stored in a freezer, and kept frozen prior to analysis. The CDD surface-snow and snow-pit samples were used to optimize the snow-sample treatment method (Sect. 3.1) and to compare our SP2 method with the thermal-optical method of OC / EC aerosol analyzer (Sect. 3.2).

\subsubsection{Caucasus high-altitude firn}

A $183 \mathrm{~m}$ ice core was drilled in September 2009 on Mt. Elbrus in the Caucasus (hereafter "ELB", $43^{\circ} 20^{\prime} \mathrm{N}, 42^{\circ} 25^{\prime} \mathrm{E}$, $5115 \mathrm{~m}$ a.s.1.). Five $1 \mathrm{~m}$ long firn sections from 7 to $12 \mathrm{~m}$ in depth were selected to compare our SP2 method with the thermal-optical method of OC/EC aerosol analyzer 
(Sect. 3.2). This is the first core from the Caucasus to be measured for rBC. Samples cover the calendar years 2006-2007, and are affected by changes in both anthropogenic and natural aerosol emissions, such as fossil fuel and biomass combustions, and dust transport from arid areas. The core was kept frozen until analysis.

\subsubsection{Greenland summit firn}

A $305 \mathrm{~m}$ long ice core was drilled in July 1989 at Summit, central Greenland (hereafter "SUM", $72^{\circ} 34^{\prime} \mathrm{N}, 37^{\circ} 38^{\prime} \mathrm{W}$, $3240 \mathrm{~m}$ a.s.1.) as part of the European EUROCORE project. Three firn sections (29.2-30, 37.9-38.2 and 64.5-64.9 m depth) were analyzed in this study, covering multi-year periods over the last 2 centuries (corresponding to 1918-1922, 1893-1894, and 1799-1800 in calendar years, respectively). The sections contain records of historical changes in both anthropogenic and natural emissions of aerosol species in the high-latitude Northern Hemisphere (Savarino and Legrand, 1998). The samples were kept frozen prior to analysis. The firn samples were analyzed for the inter-comparison of two analytical methods (Sect. 3.2).

\subsubsection{Himalayan surface snow}

Surface snow was collected at high-altitude sites in the Himalayan region in Nepal (hereafter "HIM"). The surfacesnow samples including fresh and old snow were collected at three sites near the Nepal Climate Observatory-Pyramid station (NCO-P, 5079 ma.s.1.), the Changri Nup glacier (5644 $\mathrm{m}$ a.s.1.), and the Kongma glacier (5600 m a.s.1.) located in/near the Kumbu valley. All surface snow was sampled from the surface to a depth of $10 \mathrm{~cm}$ in the period 2010 2012. The snow was sampled somewhat randomly by time and/or location due to difficult access to the snowfields. Eight samples collected in $1 \mathrm{~L}$ glass containers were analyzed for the inter-comparison of two analytical methods (Sect. 3.2). Major sources of aerosols observed in the region have been identified as biofuel combustion and transported desert dust (Bonasoni et al., 2010; Decesari et al., 2010). These snow samples melted during the transport from Nepal to Grenoble (France), which lasted for more than a week, and were later stored in the liquid phase in a refrigerator prior to analysis. Storage time varied between 1 to 2 years, depending on samples.

\section{Results and discussion}

A full evaluation and understanding of the method for the analysis of snow and ice samples with the SP2 technique is required before it can be compared with the thermaloptical method. Our discussion is thus organized along two axes: (i) how sample treatments can impact $\mathrm{rBC}$ analysis conducted with SP2 coupled with the APEX-Q nebulizer (Sect. 3.1), and (ii) which uncertainties should be considered when comparing $\mathrm{rBC}$ and EC data obtained with the two methods (Sect. 3.2).

\subsection{Treatment of the snow and ice samples before SP2 analysis}

Natural freeze/thaw cycles within snow packs that affect the size and shape of snow grains (Dominé et al., 2003) may also affect the properties of rBC particles (e.g., Flanner et al., 2012). The rBC particles can undergo physical changes during melting/refreezing processes in sample containers, depending on the procedure used to transport the samples from the field and their conservation. Recently, Schwarz et al. (2012) tested the effects of snow-sample acidification, agitation, and storage on rBC mass and size determinations. Nevertheless, the detailed, complete evaluation of snow- and ice-sample treatment prior to SP2 analysis is still necessary.

A series of tests using the natural CDD snow samples were performed to identify the optimal sample treatment to minimize losses of $\mathrm{rBC}$ particles and changes in their size distributions. We investigated the variability of $\mathrm{rBC}$ concentrations in snow samples from the top $2 \mathrm{~cm}(n=51)$ and the top $5 \mathrm{~cm}(n=5)$ layers by direct measurements without pretreatment. All the samples had comparable rBC concentration with $\mathrm{CV}$ of $18 \%$ and $17 \%$, respectively, indicating that they could be used for this comparison study. The mean of the top $2 \mathrm{~cm}$ samples $(n=5)$ in the $0.3 \mathrm{~m} \times 1.9 \mathrm{~m}$ area was very similar to that in the $0.8 \mathrm{~m} \times 1.3 \mathrm{~m}$ area $(n=46)$, with values only $3 \%$ higher.

The CDD snow was thus treated using different methods and subsequently analyzed with the SP2. We specifically investigated the impact of container condition, melting procedure, multiple melting/freezing cycles, the surface/volume ratio of the sample container, and storage procedures after melting.

\subsubsection{Choice of sample containers}

Both PP and glass were tested as vial material in this study. PP containers are widely used as snow-sample containers. Zanatta (2012) suggested that PP containers have a less absorptive and more stable surface than glass containers for rBC. More recently, Wendl et al. (2014) did not find any significant difference in $\mathrm{rBC}$ sample storage when using PP or glass containers.

We conducted blank rBC analyses in new PP containers that had been pre-rinsed with ultrapure water with and without 15 min of sonication. Blank rBC levels under both sonication conditions were $<0.01 \mu \mathrm{g} \mathrm{L}^{-1}$, based on repeated analyses. Blank levels of $\sim 0.05 \mu \mathrm{g} \mathrm{L}^{-1}$ were found after sonication for 30-45 min, but were still much lower than the lower limit of field snow- or ice-sample level, i.e., $\sim 0.1 \mu \mathrm{g} \mathrm{L}^{-1}$. Thus, all new PP containers were only prerinsed with ultrapure water before sampling. Conversely, recycled glass containers that were stored and filled with 
ultrapure water, without cleaning by sonication, were found to be significantly contaminated by rBC particles from previous samples. Blank levels of glass containers $(n=8)$ ranged between 0.1 and $12 \mu \mathrm{g} \mathrm{L}^{-1}$ after $15 \mathrm{~min}$ of sonication, but decreased to $\sim 0.01 \mu \mathrm{g} \mathrm{L}^{-1}$ or less after a second $15 \mathrm{~min}$-long sonication. This suggests potentially significant contamination of the following samples when sample-filled glass containers are sonicated without proper cleaning beforehand. Consequently, if sonication of the samples is necessary, recycled glass containers should be cleaned by $30 \mathrm{~min}$ of sonication with ultrapure water to avoid contamination of subsequent samples. As a result, we mainly used PP containers in this study, as low blank values are more easily and more consistently obtained with these containers.

\subsubsection{Effect of melting procedures}

Previous studies involving measurements of $\mathrm{rBC}$ or $\mathrm{EC}$ in snow and ice samples did not use standardized samplemelting methods. For example, snow or ice was thawed at room temperature (Jenk et al., 2006; Lavanchy et al., 1999; Thevenon et al., 2009; Wang et al., 2012); snow was melted in a warm bath $\left(<30^{\circ} \mathrm{C}\right)$ (Ming et al., 2008) or in a microwave oven (Schwarz et al., 2012); or ice was melted into discrete samples using a continuous melter system (Kaspari et al., 2011).

In this work, we tested two melting procedures whose results are listed in Table 1a. The CDD snow stored in $50 \mathrm{~mL}$ PP containers was (i) melted at room temperature for less than $2 \mathrm{~h}$, or (ii) melted in a warm water bath at $30^{\circ} \mathrm{C}$ for less than $20 \mathrm{~min}$. Mechanical stirring during melting was not used, as we observed that it did not cause any distinct change in $\mathrm{rBC}$ concentration, which is in agreement with Schwarz et al. (2012). Samples melted in a warm bath did not show a significant difference in $\mathrm{rBC}$ concentration compared to samples melted at room temperature, i.e., there was only a $3 \pm 9 \%$ increase. To investigate potential rBC losses during melting, all the samples were measured a second time after $15 \mathrm{~min}$ of sonication. No changes in rBC concentrations were observed before and after sonication in samples initially melted at room temperature. The samples melted in a warm bath exhibited a slight increase $(12 \pm 18 \%)$ in $\mathrm{rBC}$ concentration after sonication, which we did not consider to be critical due to a relatively larger standard deviation for the smaller number of samples $(n=10)$.

These results showed that melting samples at room temperature in less than $2 \mathrm{~h}$ caused no additional rBC losses compared to melting in a warm bath for a shorter time, i.e., in less than $20 \mathrm{~min}$, although it is generally thought that faster melting leads to fewer rBC particle losses. Sample treatment with sonication is also unnecessary when samples are melted rapidly (i.e., in less than $2 \mathrm{~h}$ ). However, rapid melting in a warm bath or applying sonication after melting does not cause significant differences compared to more straightforward melting at room temperature without sonication.

\subsubsection{Effect of multiple melting/freezing/melting cycles}

Refreezing/melting processes may lead to the redistribution of particles in a sample container (e.g., particles sticking to the wall of the container). To simulate a melting/freezing/melting cycle, snow samples were refrozen immediately after analysis and then remelted at room temperature for less than $2 \mathrm{~h}$ prior to a second analysis. Interestingly, there was a marked decrease in $\mathrm{rBC}$ concentrations during this process $(45 \pm 11 \%$, Table $1 \mathrm{~b})$. We thus suggest that the observed loss of rBC particles happened during freezing of the sample, as we previously demonstrated that melting had no impact if conducted within $2 \mathrm{~h}$ (Table 1a). The remelted samples were then treated using different methods to investigate $\mathrm{rBC}$ recovery after freezing ( $n=5$ for each method, Table $1 \mathrm{~b}$ ): ultra-sonication (for 15, 30, and $45 \mathrm{~min}$ ), and acidification. $\mathrm{rBC}$ losses of $38 \pm 16 \%$ were still recorded after $15 \mathrm{~min}$ of sonication, but decreased to $14 \pm 14 \%$ after $30 \mathrm{~min}$ of sonication. Sonication for $45 \mathrm{~min}$ was no more efficient. Sonication for $30 \mathrm{~min}$ led to the highest $\mathrm{rBC}$ recovery rate observed after a freezing/remelting cycle. In addition, the tested samples $(n=3)$ were refrozen, remelted (thus, artificially refrozen two times in total) and analyzed, which showed rBC total mass reduction of $\sim 50-70 \%$ and 30 min of sonication helped only $\sim 10 \%$ increase in rBC mass concentration. We observed significant $\mathrm{rBC}$ losses over all size ranges in the remelted samples, and the lost $\mathrm{rBC}$ particles were recovered uniformly over almost all size ranges after $30 \mathrm{~min}$ of sonication. We also acidified samples with $0.5 \mathrm{M}$ nitric acid, following the procedure described by Kaspari et al. (2011). Acidification did not reduce losses of $\mathrm{rBC}$ after a freezing/remelting cycle (0\% variation).

\subsubsection{Effect of the surface/volume ratio of sample containers}

The surface/volume $(S / V)$ ratio of sample containers may affect $\mathrm{rBC}$ losses that occur during a melting/freezing cycle. This concern arose because our main assumption concerning $\mathrm{rBC}$ losses in a container is particles adhering on the wall of the container. Two types of PP containers with different $S / V$ ratios were used to test this hypothesis: a $50 \mathrm{~mL} \mathrm{PP}$ tube container with $S=22.9 \mathrm{~cm}^{2}$ and $V=10 \mathrm{~mL}$ of the samples $\left(N=5, S / V=2.3 \mathrm{~cm}^{2} \mathrm{~mL}^{-1}\right)$, and a $125 \mathrm{~mL}$ cylindrical PP container with $S=75.4 \mathrm{~cm}^{2}$ and $V=30 \mathrm{~mL}$ of the samples $\left(N=5, S / V=2.5 \mathrm{~cm}^{2} \mathrm{~mL}^{-1}\right)$. The $125 \mathrm{~mL}$ containers had a $10 \%$ larger $S / V$ than the $50 \mathrm{~mL}$ containers. After refreezing/melting, average $\mathrm{rBC}$ mass losses from the two containers were $37 \pm 14 \%$ and $55 \pm 30 \%$, respectively (Table 1c). After $30 \mathrm{~min}$ of sonication, $\mathrm{rBC}$ losses from the $125 \mathrm{~mL}$ container were still $41 \pm 34 \%$, while more particles were recovered from the $50 \mathrm{~mL}$ containers, with $\mathrm{rBC}$ losses of only $11 \pm 26 \%$. This result suggests that the $S / V$ ratio can influence rBC losses during cycles of refreezing/melting, 
Table 1. rBC concentrations in snow samples from Col du Dôme (CDD, French Alps) determined after different treatment: (a) melting procedure, (b) freezing/melting cycle, (c) surface to volume ratios of the container, and (d) storage. $\mathrm{rBC}$ refers to the mean $\mathrm{rBC}( \pm 1$ standard deviation) concentration calculated over $N$ samples. $\Delta(\mathrm{rBC})$ refers to $\%$ variations in $\mathrm{rBC}$ concentrations between the reference and the treatment concerned. US stands for "ultrasonication". * indicates data collected after refreezing and remelting samples.

\begin{tabular}{|c|c|c|c|c|c|c|c|c|}
\hline$N$ & $\begin{array}{l}\mathrm{rBC} \\
\left(\mu \mathrm{g} \mathrm{L}^{-1}\right)\end{array}$ & $\begin{array}{l}\Delta \mathrm{rBC} \\
(\%)\end{array}$ & $\begin{array}{l}\text { Treatment } \\
\text { description }\end{array}$ & Refreezing & $\begin{array}{l}\mathrm{rBC} \\
\left(\mu \mathrm{gL}^{-1}\right)^{*}\end{array}$ & $\begin{array}{l}\Delta \mathrm{rBC} \\
(\%)^{*}\end{array}$ & $\begin{array}{l}\text { Treatment } \\
\text { description* }\end{array}$ & Comments \\
\hline \multicolumn{9}{|c|}{ (a) Melting procedure } \\
\hline 41 & $\begin{array}{l}4.7 \pm 1.0 \\
4.7 \pm 1.1\end{array}$ & $\begin{array}{l}\text { Reference } \\
0 \pm 24\end{array}$ & $\begin{array}{l}\text { Melting at room temp. } \\
\text { and US } 15 \mathrm{~min}\end{array}$ & $\mathrm{X}$ & & & & \\
\hline 10 & $\begin{array}{l}4.9 \pm 0.4 \\
5.3 \pm 0.8\end{array}$ & $\begin{array}{l}3 \pm 9 \\
12 \pm 18\end{array}$ & $\begin{array}{l}30^{\circ} \mathrm{C} \text { melting } \\
\text { and US } 15 \mathrm{~min}\end{array}$ & $\mathrm{X}$ & & & & \\
\hline \multicolumn{9}{|c|}{ (b) Freezing/melting cycle } \\
\hline 5 & $5.8 \pm 1.3$ & Reference & Melting at room temp. & $\Rightarrow$ & $\begin{array}{l}3.5 \pm 1.3 \\
3.6 \pm 1.0\end{array}$ & $\begin{array}{l}-40 \pm 21 \\
-38 \pm 16\end{array}$ & $\begin{array}{l}\text { Remelting at } \\
\text { room temp. } \\
\text { and US } 15 \mathrm{~min}\end{array}$ & \\
\hline 5 & $5.0 \pm 1.3$ & Reference & Melting at room temp. & $\Rightarrow$ & $\begin{array}{l}2.4 \pm 0.3 \\
4.3 \pm 0.7\end{array}$ & $\begin{array}{l}-52 \pm 6 \\
-14 \pm 14\end{array}$ & $\begin{array}{l}\text { Remelting at } \\
\text { room temp. } \\
\text { and US } 30 \mathrm{~min} \text {. }\end{array}$ & \\
\hline 5 & $3.9 \pm 0.4$ & Reference & Melting at room temp. & $\Rightarrow$ & $\begin{array}{l}2.1 \pm 0.3 \\
3.1 \pm 1.0\end{array}$ & $\begin{array}{l}-46 \pm 7 \\
-21 \pm 25\end{array}$ & $\begin{array}{l}\text { Remelting at } \\
\text { room temp. } \\
\text { and US } 45 \mathrm{~min} \text {. }\end{array}$ & \\
\hline 5 & $4.0 \pm 0.4$ & Reference & Melting at room temp. & $\Rightarrow$ & $\begin{array}{l}2.4 \pm 0.4 \\
2.4 \pm 0.3\end{array}$ & $\begin{array}{l}-41 \pm 10 \\
-41 \pm 7\end{array}$ & $\begin{array}{l}\text { Remelting at } \\
\text { room temp. } \\
\text { and acidification }\end{array}$ & \\
\hline \multicolumn{9}{|c|}{ (c) Surface / volume ratio of the container } \\
\hline 5 & $4.9 \pm 0.8$ & Reference & Melting at room temp. & $\Rightarrow$ & $\begin{array}{l}3.1 \pm 0.7 \\
4.3 \pm 1.3\end{array}$ & $\begin{array}{l}-37 \pm 14 \\
-11 \pm 26\end{array}$ & $\begin{array}{l}\text { Remelting at } \\
\text { room temp. } \\
\text { and US } 30 \text { min. }\end{array}$ & $50 \mathrm{~mL}$ PP container \\
\hline 5 & $7.8 \pm 1.3$ & Reference & Melting at room temp. & $\Rightarrow$ & $\begin{array}{l}3.5 \pm 2.4 \\
4.6 \pm 2.6\end{array}$ & $\begin{array}{l}-55 \pm 30 \\
-41 \pm 34\end{array}$ & $\begin{array}{l}\text { Remelting at } \\
\text { room temp. } \\
\text { and US } 30 \mathrm{~min} \text {. }\end{array}$ & $125 \mathrm{~mL}$ PP container \\
\hline & torage & & & & & & & \\
\hline 5 & $\begin{array}{l}4.9 \pm 0.3 \\
5.0 \pm 0.4 \\
5.3 \pm 1.0 \\
4.7 \pm 0.6 \\
4.4 \pm 0.8\end{array}$ & $\begin{array}{l}\text { Reference } \\
3 \pm 9 \\
9 \pm 20 \\
-3 \pm 11 \\
-9 \pm 17\end{array}$ & $\begin{array}{l}\text { Melting at room temp. } \\
\text { and storage at room } \\
\text { temp. for } 2 \mathrm{~h} \\
\text { and storage at room } \\
\text { temp. for } 4 \mathrm{~h} \\
\text { and storage at room } \\
\text { temp. for } 6 \mathrm{~h} \\
\text { and storage at room } \\
\text { temp. for } 24 \mathrm{~h}\end{array}$ & $\mathrm{X}$ & & & & \\
\hline 5 & $\begin{array}{l}4.7 \pm 0.3 \\
4.6 \pm 0.3 \\
4.4 \pm 0.1 \\
4.4 \pm 0.1 \\
4.6 \pm 0.3\end{array}$ & $\begin{array}{l}\text { Reference } \\
-3 \pm 6 \\
-6 \pm 3 \\
-6 \pm 3 \\
-3 \pm 6\end{array}$ & $\begin{array}{l}\text { Melting at room temp. } \\
\text { and storage in the } \\
\text { refrigerator for } 2 \mathrm{~h} \\
\text { and storage in the } \\
\text { refrigerator for } 4 \mathrm{~h} \\
\text { and storage in the } \\
\text { refrigerator for } 6 \mathrm{~h} \\
\text { and storage in the } \\
\text { refrigerator for } 24 \mathrm{~h}\end{array}$ & $\mathrm{X}$ & & & & \\
\hline
\end{tabular}


although measuring more samples would be required to provide statistically significant conclusions.

\subsubsection{Effect of storage procedures after melting}

Snow samples stored in PP containers were first analyzed without treatment (e.g., sonication or acidification) and stored at room temperature $\left(5-15^{\circ} \mathrm{C}\right)$ or in a refrigerator $\left(4.5^{\circ} \mathrm{C}\right)$ to evaluate $\mathrm{rBC}$ losses as a function of time. These samples were analyzed 2, 4, 6, and $24 \mathrm{~h}$ after the first melt cycle, without any additional treatment. Changes in mean rBC concentrations were not significant in the samples maintained at room temperature, but their concentrations were more variable than in samples kept in the refrigerator (Table $1 \mathrm{~d})$. However, after $24 \mathrm{~h}$ at room temperature, the change in $\mathrm{rBC}$ concentrations was slight $(-9 \pm 17 \%)$, particularly compared to the $\mathrm{rBC}$ losses during refreezing/melting.

When rBC concentrations were monitored in samples stored in glass containers at room temperature for $24 \mathrm{~h}$, similar results were observed. Schwarz et al. (2012) also mentioned that $\mathrm{rBC}$ losses in glass containers stored at room temperature were limited, although they showed that losses were higher (about 50\%) in high-density polyethylene bottles.

rBC mass losses in PP containers that were kept in the refrigerator remained constant for $24 \mathrm{~h}$ with $-3 \pm 6 \%$ change. The same snow samples were kept in the refrigerator for a week and $\mathrm{rBC}$ was then analyzed again. Changes in $\mathrm{rBC}$ masses after a week were $-13 \%$ on average, a value that was reduced to $-7 \%$ after 15 min of sonication. Sonication thus helps recover $\mathrm{rBC}$ particles in samples stored in the liquid phase for more than 1 day.

\subsubsection{Summary}

According to the series of tests described in Sect. 3.1, we recommend the following method to minimize a reduction in $\mathrm{rBC}$ concentrations and changes in associated $\mathrm{rBC}$ size distributions when measuring snow or ice samples.

- Samples should ideally be stored in new polypropylene (PP) containers, which are pre-rinsed with ultrapure water. The container should have the smallest possible surface/volume ratio. Recycled glass containers should be cleaned by intense sonication ( $30 \mathrm{~min}$ ), especially if samples need to be sonicated before analysis.

- Melting should be rapid (e.g., $<2$ h), in which case additional treatments such as sonication are not necessary. Refreezing samples should be avoided. Remelted samples showed $\mathrm{rBC}$ mass losses of $-45 \pm 11 \%$ in $50 \mathrm{~mL}$ PP containers. If samples are melted either partially or entirely, sonication for $30 \mathrm{~min}$ is recommended. After 30 min of sonication, the $\mathrm{rBC}$ mass losses were reduced by a factor of $\sim 3$.
- If samples have to be kept in the liquid phase for a few hours prior to analysis, storing them for 1 day in a refrigerator or at room temperature will not lead to serious rBC losses $(<10 \%)$.

\subsection{Comparison between the SP2 and the thermal-optical method}

Inter-comparison of the SP2-based method and the thermaloptical method has been carried out for BC aerosol samples (e.g., Kondo et al., 2011; Laborde et al., 2012b). Similar studies for snow and ice samples are available only for the intercomparison between the SP2-based method and the lightabsorption method (e.g., Schwarz et al., 2012). Here, we report the results of a comparison between our SP2 method (Sects. 2.1, 2.2 and 3.1) and the thermal-optical method of Sunset OC/EC aerosol analyzer, operated using the EUSAAR2 protocol (Sects. 2.3 and 3.1). Snow and firn of various origins were used to better characterize the limitations of the two approaches. Specifically, SUM and ELB firn, and CDD and HIM snow (Sect. 2.4), were analyzed with both the SP2 and the Sunset OC/EC analyzer.

Considering their large volume in $1 \mathrm{~L}$ glass containers, snow and firn were melted in a warm bath to minimize melting time. Only the HIM snow was sonicated for $15 \mathrm{~min}$ to avoid $\mathrm{rBC}$ particle loss on the container walls since they had been stored in the liquid phase. The melted samples were filtrated and split into aliquots for immediate rBC analysis by the SP2 (10 mL PP) and dust analysis by a Coulter Counter Multisizer 3 (10 mL accuvette) (Beckman Coulter, Inc, USA) in a 100 class clean room. Filtration was carefully performed using the method described in the Supplement. The $\mathrm{EC}$ and $\mathrm{rBC}$ concentrations and $\mathrm{EC} / \mathrm{rBC}$ ratios are listed in Table 2. Note that all $\mathrm{rBC}$ data were corrected for losses during the aerosolization processes through daily calibration (see Sect. 2.2.4). We observed significant differences between the two techniques with $\mathrm{EC} / \mathrm{rBC}$ ratios ranging from 0.5 to 3.4 , depending on the sample origin. In the following, we discuss the artifacts that could have led to these discrepancies between the two techniques.

\subsubsection{Measurement sensitivity to SP2 mass detection range}

Size distributions of BC particles mainly depend on emission sources and atmospheric processes, and range from a few nanometers to a few micrometers (Bond et al., 2013). As mentioned in Sect. 2.1.2, the SP2 used in this study provided $\mathrm{rBC}$ particle size distribution between $\sim 60$ and $620 \mathrm{~nm}$ MED, and particles larger than $620 \mathrm{~nm}$ were considered by the analyzer to be particles with a diameter of $620 \mathrm{~nm}$ due to the detector saturation. However, less than $0.1 \%$ of the total number of $\mathrm{rBC}$ particles in all the samples we tested was found at the saturation point $(620 \mathrm{~nm})$. In particular, the contribution of $\mathrm{rBC}$ at saturation point in the SUM and CDD samples represented less than $0.05 \%$ of total $\mathrm{rBC}$. Assuming 


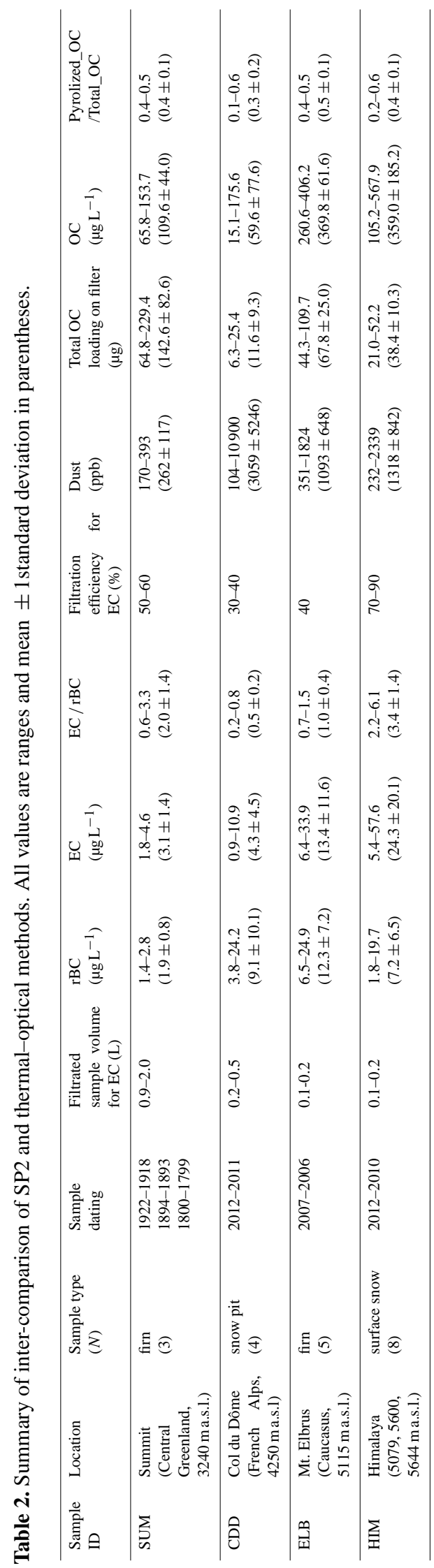

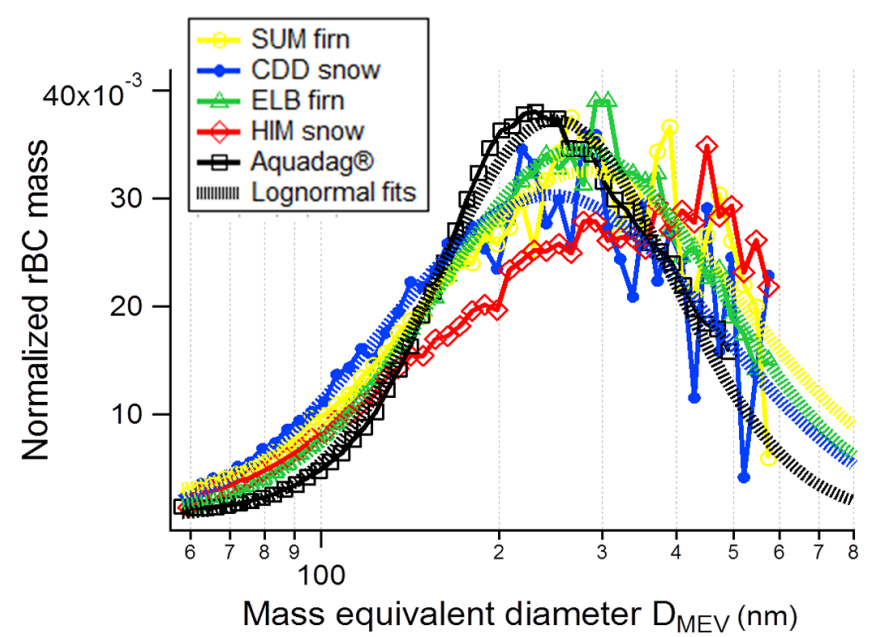

Figure 2. Mass size distributions of $\mathrm{rBC}$ in snow and firn samples from the different sites investigated. The $y$ axis is $\mathrm{d} M / \mathrm{d} \log \left(D_{\mathrm{MED}}\right)$ with all distributions normalized to an area of 1 . Histogram bin size is 50 .

that $\mathrm{rBC}$ size distributions in snow samples can be lognormal fitted (e.g., Fig. 2), one can estimate that a $0.05-0.1 \%$ contribution of large particles detected at saturation represents less than $12 \%$ of the total $\mathrm{rBC}$ mass. Such calculation could not be applied for the snow samples collected in semi-rural and rural areas, as demonstrated by Schwarz et al. (2012). These authors observed occurrences of particles larger than $1 \mu \mathrm{m}$ in snow collected within $60 \mathrm{~km}$ of Denver (USA). Similarly, this calculation would likely not be accurate for samples experiencing freezing/thawing cycles which might affect particle sizes. In this study, the CDD, ELB, and SUM samples were all collected at high-altitude and remote sites, and the reference analyses on these samples (see Sect. 3.1) were always conducted just after melting. However, the HIM samples were transported after collection during more than 1 week at room temperature, and then stored in a refrigerator for more than 1 year before analysis. Interestingly, the HIM samples also showed a significant shift towards larger sizes compared to samples from other sites (Fig. 2). These larger rBC sizes observed for HIM snow samples may be natural, but could also originate from the transportation at room temperature and long storage. Finally, we conclude that the analyses conducted in this study on CDD, ELB, and SUM are only slightly affected by the inadequate SP2 detection range, but that this artefact is larger for HIM samples.

Thus, an accurate determination of $\mathrm{rBC}$ mass in snow and ice samples may require an optimization of the analyzer settings in order to enlarge detection range up to micrometer particles. This is possible, as demonstrated recently by Schwarz et al. (2012) and Wendl et al. (2014) who extended their SP2 detection ranges to 2000 and $800 \mathrm{~nm}$ MED, respectively. 


\subsubsection{EC artifact due to inadequate filtration}

To our knowledge, there is no size limitation in the thermaloptical method, which can theoretically analyze all EC particles on the filter. However, the sample filtration step may involve EC losses, especially of fine particles that can pass through the filter with the sample water. The EC losses that occurred during filtration of sample water were investigated by Ducret and Cachier (1992), Lavanchy et al. (1999), and Hadley et al. (2008). Overall, these authors concluded that collection efficiency was almost above $92 \%$. More recently, Torres et al. (2014) evaluated filtration efficiencies ranging $10-38 \%$ for rainwater samples by applying SP2 analysis to samples before and after filtration. We followed a similar approach, investigating the SP2-based filtration efficiency (FE) of $\mathrm{rBC}$ particles collected on quartz fiber filter as follows:

$\mathrm{FE}=$
$1-\frac{\mathrm{rBC} \text { mass concentration in sample after filtration }}{\mathrm{rBC} \text { mass concentration in sample before filtration }}$.

All samples showed a significant fraction of $\mathrm{rBC}$ that was not retained on the filter during filtration, and consequently not measured by the thermal-optical method (Table 2). The size of the particles filtered was found to strongly affect the FE, and, consequently, the subsequent EC analysis with thermal-optical analyzer. Size distributions determined for all ELB and CDD samples before and after filtration revealed a strong dependence of the filtration efficiency with the particle MED (Fig. 3). FE decreased to $20 \%$ for particles $<200 \mathrm{~nm}$ MED, and exceeded $65 \%$ for particles $>500 \mathrm{~nm}$. Only $\sim 30-40 \%$ of rBC mass in CDD snow samples was retained by the quartz filter. In contrast, we observed a much higher filtration efficiency for the HIM samples with FE ranging from 70 to $90 \%$. These observations are in good agreement with size distributions showing the occurrence of small particles for CDD samples, and large particles for HIM samples (Fig. 2). To support this conclusion, the liquid collected after filtration of a CDD sample was filtrated again on a $0.2 \mu \mathrm{m}$ nuclepore and observed by electron microscopy. BC aggregates with diameters ranging between 100 and $200 \mathrm{~nm}$ were frequently visible in microscopy images, contrary to larger BC particles (Fig. S3 in the Supplement). These images confirm that small particles can easily pass through quartz filters during filtration.

Interestingly, our data suggest that FE might also be influenced by the amount of OC loaded on the quartz filter. ELB and SUM samples showed intermediate filtration efficiencies $(\sim 40-60 \%)$. These samples show slightly larger MMD (Fig. 2), which can contribute to more efficient filtrations. However, these samples were also characterized by larger OC masses loaded on the filters compared to CDD samples $(67.8 \pm 25.0 \mu \mathrm{g}$ and $142.6 \pm 82.6 \mu \mathrm{g}$ for ELB and SUM samples, respectively). We cannot rule out that OC favors retention of $\mathrm{rBC}$ on filters, although this hypothesis

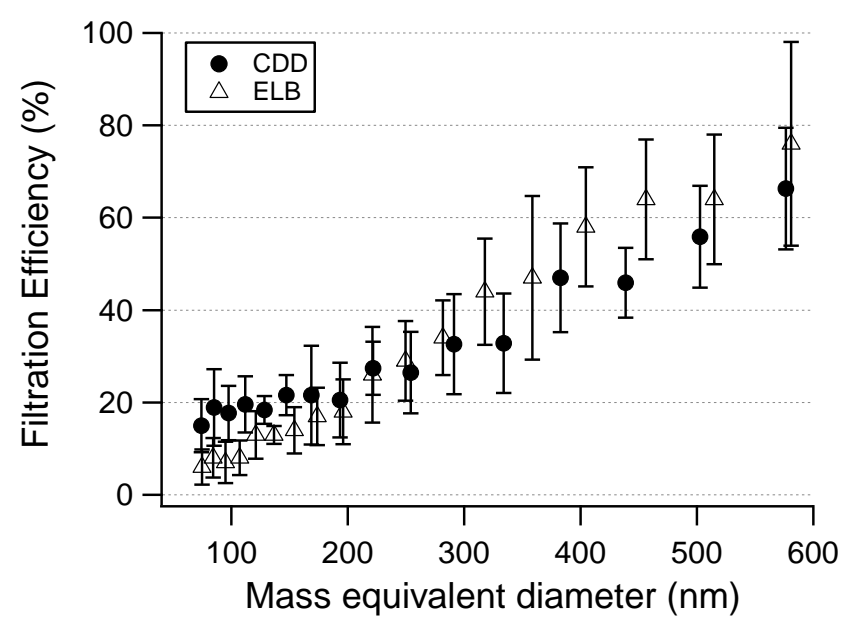

Figure 3. SP2-based filtration efficiency (FE) of rBC particles collected on quartz filter for CDD and ELB samples. The whiskers stand for one standard deviation.

remains highly speculative with undetermined processes involved. Contrarily, elevated dust loading on the quartz filters did not increase FE. Highly dusty CDD samples (dust concentration of $10.9 \mathrm{ppm}$, corresponding to a loaded dust mass on the filter of $1744 \mu \mathrm{g}$ ) exhibited a low FE, similar to other CDD samples.

Finally, the sample volume filtered could also influence $\mathrm{FE}$ as a consequence of the above artifact related to OC loading on filters. As an illustration, the SUM samples showed low OC concentrations, but a significant OC mass could be loaded on the quartz filters due to their large volumes filtered $(\sim 1-2 \mathrm{~L}$, Table 2$)$.

rBC particle sizes, possibly OC loading on filters and sample volumes filtered affect $\mathrm{FE}$ and consequently the EC quantification using a thermal-optical analyzer. Previous snow and ice studies reporting concentrations of EC determined using quartz filters (e.g., Hagler et al., 2007; Lavanchy et al. 1999; Ming et al., 2008, 2009; Thevenon et al. 2009) may have underestimated EC concentration by a significant but, as yet, unquantifiable factor. Our results further suggest that this factor can vary depending on samples. Torres et al. (2014) demonstrated that FE can be increased up to $95 \%$ by adding salts and acid into rainwater samples. Such approach should be investigated as well for snow and ice samples.

\subsubsection{Artifact due to the presence of dust}

High levels of dust in liquid samples may affect both $\mathrm{rBC}$ and EC determinations (Schwarz et al., 2012; Wang et al., 2012). The impact of dust on the SP2-based rBC analysis is not discussed in this study. Schwarz et al. (2012) conservatively estimated an $\mathrm{rBC}$ artifact to be $\mathrm{a}+15 \mathrm{ng} \mathrm{g}^{-1}$ offset in a highly dust-contaminated laboratory sample, i.e., with dust levels reaching $50 \mathrm{ppm}$. Note that such elevated dust levels 


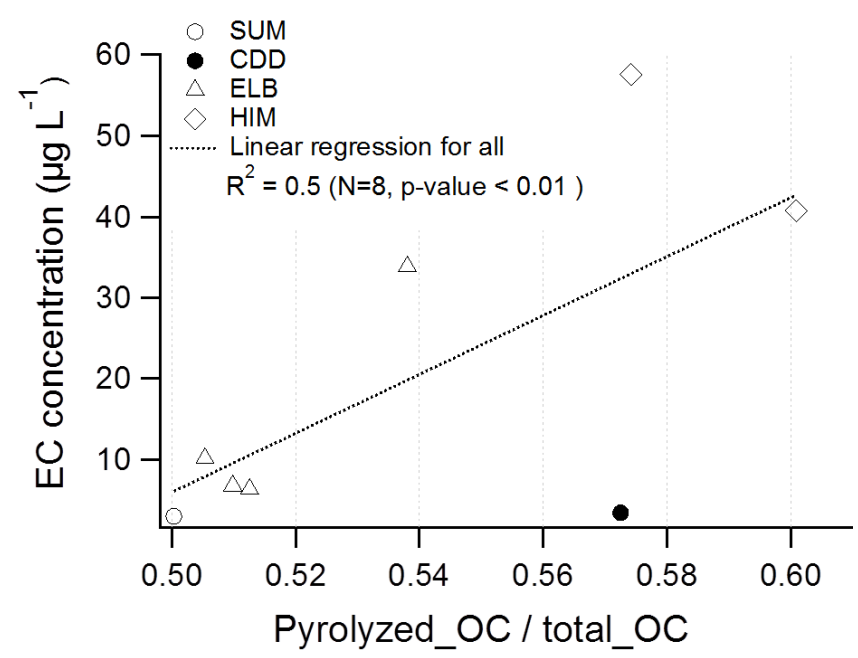

Figure 4. Comparison of pyrolyzed_OC/total_OC ratio and EC concentration for all snow and firn samples showing values of pyrolyzed_OC/total_OC ratio $>0.5$.

were never observed for any CDD, ELB, SUM, or HIM samples (Table 2).

The impact of dust on the thermal-optical method has been addressed in previous laboratory studies (e.g., Chow et al., 2001; Wang et al., 2012). Dust particles including catalytically active ions or mineral oxides (e.g., hematite) can reduce the sensitivity of the instrument (Chow et al., 2001) but also bias the OC/EC split point during the analysis by delaying or preventing the laser signal from reaching its initial value (Wang et al., 2012). Consequently, EC concentrations of dusty samples are generally underestimated or not determined. In this study, however, we observed a lack of a systematic correlation between EC and dust concentration.

The thermograms of OC/EC analysis of the dusty CDD snow layers 2 and 3 (dust concentrations of $\sim 1$ and $\sim 11$ ppm, respectively) reveal such artifacts. The laser signal did not return to its baseline value before the end of analysis, resulting in no EC fraction. The yellowish or dark brown color of these snow samples changed to red brown color after combustion, indicating the existence of hematite. To eliminate the impact of dust on incomplete OC/EC splitting, the results were revised following procedures described by Wang et al. (2012). It should be noted that this revision was somewhat rough, as we did it by visually modifying the initial laser transmittance value line in the thermograms, and these revised concentrations are listed in Table 2. Interestingly, we did not always observe artifacts on Sunset thermograms when we analyzed highly dusty samples from other sites (e.g., HIM samples). Consequently, we conclude that not only the concentration but also the type of dust can lead to analytical failure in EC measurements. Finally, we recommend systematic evaluation of the thermogram during EC analysis, particularly if the sampling site is influenced by local or regional dust sources.

\subsubsection{EC artifact due to OC pyrolyzation}

OC pyrolysis, which occurs during thermal-optical EC detection, could affect EC determination by biasing the OC/EC split point and then generally causing a positive EC artifact, if not properly corrected (Chow et al., 2001; Schmid et al., 2001). $40 \%$ of the snow and firn samples that we tested $(n=20)$ revealed a pyrolyzed OC fraction representing more than half of the total OC, i.e., pyrolyzed_OC/total_OC ratio $\geq 0.5$, which is rarely observed in atmospheric samples at French urban sites (unpublished data). Figure 4 illustrates the relationship between pyrolyzed_OC/total_OC ratio and EC concentration for samples with pyrolyzed_OC/total_OC ratio $\geq 0.5(n=8)$. The EC concentration generally increased with an increase in the pyrolyzed_OC/total_OC ratio, with a Pearson correlation coefficient $\left(r^{2}\right)$ of 0.5 ( $p$ value $<0.01$ ). Conversely, no linear relationship of pyrolyzed_OC/total_OC ratio and rBC concentration was observed for these samples $\left(r^{2}<0.1\right)$. Previous studies reported that some non-volatile OC fractions, either OC with high-molecular weight (Miyazaki et al., 2007; Yu et al., 2004) or HULIS (Cavalli et al., 2010; Clarke et al., 2007; Kondo et al., 2011), are prone to pyrolysis during the thermal analysis. We cannot confirm which organic fractions underwent pyrolysis in our samples. However, this result clearly suggests that the higher pyrolyzed OC fraction probably causes a positive EC artifact in the snow and firn samples by biasing the OC / EC split point, and consequently leading a fraction of pyrolyzed OC to be determined as EC.

We observed lower OC concentrations in SUM samples $(n=3)$ than in ELB and HIM samples, but the large volumes of SUM samples filtered for EC analysis meant that a higher OC mass was loaded on the filter in the case of SUM samples $(143 \pm 83 \mu \mathrm{g})$. The SUM samples showed a positive relationship between pyrolyzed_OC/total_OC ratio and OC mass loading on the filter. We consequently suggest that the elevated $\mathrm{EC} / \mathrm{rBC}$ ratio of $2.0 \pm 1.4$ observed in the SUM samples (Table 2 ) may be partially and indirectly explained by the large sample volumes used. This means that appropriate sample volumes should be carefully chosen and applied during EC filtration for thermal-optical analysis to reduce potential uncertainties.

\section{Conclusions}

We evaluated an $\mathrm{rBC}$ measurement methodology coupling jet nebulizer (APEX-Q) and the SP2 analyzer, through an extended series of tests using both $\mathrm{rBC}$ standard material and various types of snow and firn collected from different glaciers worldwide. Before applying the APEX-Q/SP2 to field sample analysis, we compared two different nebulizers: APEX-Q and U5000AT. We found that the APEX-Q is more suitable for snow and ice analysis for the following reasons. The aerosolization efficiency tests, using PSLs with known 
Table 3. Evaluation of advantages and disadvantages of the SP2-based method and the thermal-optical method.

\begin{tabular}{|c|c|c|}
\hline $\begin{array}{l}\text { Analytical method } \\
\text { (BC terminology) }\end{array}$ & Advantages & Disadvantages \\
\hline \multirow{7}{*}{$\begin{array}{l}\text { Single particle soot } \\
\text { photometer } \\
\text { (rBC) }\end{array}$} & - Precise and reproducible & - rBC loss during aerosolization \\
\hline & $\begin{array}{l}\text { - Provide rBC size information } \\
\text { (mass-equivalent diameter) }\end{array}$ & $\begin{array}{l}\text { - Limited detection range } \\
\text { (depending on SP2 detector setting) }\end{array}$ \\
\hline & - No interference from OC & $\begin{array}{l}\text { - Ununified calibration material for } \mathrm{rBC} \text { mass } \\
\text { (internal calibration) }\end{array}$ \\
\hline & - Low detection limit $\left(0.01 \mu \mathrm{g} \mathrm{L}^{-1}\right)$ & $\begin{array}{l}\text { - Need of devices for internal calibration } \\
\text { (e.g., Scanning mobility particle sizer, Conden- } \\
\text { sation particle counter, etc.) }\end{array}$ \\
\hline & - Small sample volume $(<1-2 \mathrm{~mL})$ & - Relatively tricky data retrieval \\
\hline & - Fast analysis $(<10 \mathrm{~min})$ & \\
\hline & - Continuous analysis possible & \\
\hline \multirow{6}{*}{$\begin{array}{l}\text { Thermal-optical } \\
\text { analysis } \\
\text { (EC) }\end{array}$} & - Precise and reproducible & - Potential positive artifact from pyrolyzed OC \\
\hline & - Fast analysis $(<20 \mathrm{~min})$ & $\begin{array}{l}\text { - Incomplete and variable filtration on quartz } \\
\text { filters }\end{array}$ \\
\hline & - No upper limit in particle size detection & - Potential artifact from dust \\
\hline & $\begin{array}{l}\text { - Useful to obtain actual rBC mass } \\
\text { of rBC standard for SP2 analysis }\end{array}$ & $\begin{array}{l}\text { - Large sample volume required }(0.1-2 \mathrm{~L} \text {, } \\
\text { depending on the EC loading) }\end{array}$ \\
\hline & - Easy data retrieval & - Sample decarbonation often required \\
\hline & & $\begin{array}{l}\text { - Contamination can occur during the long } \\
\text { sample preparation procedure } \\
\text { (e.g., filtration and drying filter, and chemical } \\
\text { decarbonation takes }>4 \text { days) }\end{array}$ \\
\hline
\end{tabular}

diameters, revealed the particle size-independent aerosolization capability in the APEX-Q, ensuring an accurate $\mathrm{rBC}$ size-distribution determination. In contrast, the U5000AT has a strong size-dependent efficiency (Schwarz et al., 2012; Wendl et al., 2014). We showed that aerosolization was more efficient with APEX-Q than with U5000AT nebulizer, with $75 \pm 7 \%$ and $30 \pm 3 \%$ efficiency, respectively. The APEX$\mathrm{Q}$ led to better aerosolization of large $\mathrm{rBC}$ particles with a consumption of much smaller sample volume. Furthermore, to avoid potential rBC losses and changes in $\mathrm{rBC}$ size distribution of snow and ice samples, we propose a series of recommendations concerning the choice of container, first melting of the sample, melting/freezing/melting cycles, surface/volume ratio of the sample container, and storage.
These sample treatment methods could also be applied before determination of EC using thermal-optical methods.

An inter-comparison between the SP2-based method and the thermal-optical (Sunset OC/EC aerosol analyzer with EUSAAR2 protocol) method was conducted using optimized setups with four different types of samples: Greenland summit firn core (SUM), surface high-altitude alpine snow (CDD), firn from the Caucasus region (ELB), and Himalayan surface snow (HIM). The strengths and weaknesses of both methods are summarized in Table 3. We observed differences between EC and $\mathrm{rBC}$, which were not constant in the different samples and reflected analytical artifacts potentially affecting both analytical methods. The lowest EC / rBC ratio values were found for the CDD samples $(0.5 \pm 0.2$; Table 2) and highlight the incomplete retention of $\mathrm{rBC}$ particles 
during the sample filtrations required for thermal-optical analyses. Our study demonstrates that filtration efficiency on quartz fiber filters strongly decreases with decrease of $\mathrm{rBC}$ particle size, causing EC underestimation by the thermaloptical analyzer. The SUM samples showed high and variable EC / rBC ratios (2.0 \pm 1.4 ; Table 2), which could be explained by elevated and variable OC loading on the quartz filters. Such large OC loading is indirectly driven by the sample volume filtered. Although highly speculative, it is possible that both volume and $\mathrm{OC}$ concentration of a sample can affect its EC determination. A good agreement between EC and $\mathrm{rBC}$ was found for the ELB samples $(\mathrm{EC} / \mathrm{rBC}$ ratios: $1.0 \pm 0.4$; Table 2). Such agreement could be the result of (i) EC underestimation driven by low filtration efficiency and (ii) EC overestimation caused by non-negligible OC loading on filters. Finally, the HIM samples exhibited the highest $\mathrm{EC} / \mathrm{rBC}$ ratio (3.4 \pm 1.4 ; Table 2$)$, although filtration efficiencies ranged between 70 and $90 \%$. We explain the relatively lower HIM rBC values by an inadequate size-detection range of the SP2 analyzer. It is likely that a large amount of rBC mass in the HIM samples consisted of particles larger than $620 \mathrm{~nm}$, i.e., the upper limit of the SP2 size-detection range in this study, but which was not clear if the large particles occurred naturally or artificially. Note that $\mathrm{rBC}$ underestimation caused by this artifact for CDD, ELB, and SUM samples should be lower than $12 \%$ when $\mathrm{rBC}$ size distributions in snow and firn samples are log-normal fitted. Thus, this does not affect our previous interpretation.

Finally, the APEX-Q/SP2 coupling can provide an optimized method for accurate measurements of $\mathrm{rBC}$ mass concentrations and size distributions in snow and ice samples, as long as the SP2 size-detection range is adapted to the sample analyzed. Note that modification of the detector gains allows to increase the upper limit of the SP2 size-detection range as reported by Schwarz et al. (2012) or Wendl et al. (2014). Thermal-optical measurements of EC in snow samples might be more challenging, and three important recommendations can be extracted from our study: (i) specific evaluation of the filtration efficiency is required for different samples, (ii) monitoring and correction of thermograms are needed for highly-dusty samples, and (iii) modification of temperature program can limit the effect of dust or pyrolyzed OC fraction on the OC / EC split point. We advise that further studies reach quantification of these artifacts by conducting more tests with laboratory samples of known sizes, concentration, and chemical content (e.g., based on AQ solutions). The Supplement related to this article is available online
at doi:10.5194/amt-7-3307-2014-supplement.
Acknowledgements. This work was supported by the EU FP7 IP PEGASOS (FP7-ENV- 2010/265148), the French ANR programs RPD COCLICO (ANR-10-RPDOC-002-01), PAPRIKA (ANR09-CEP-005-02) and OSUG@2020 (Investissements d'avenir ANR10LABX56). Support was also supplied by the Korean Ministry of Education and Science Technology through a government scholarship for S. Lim. We thank M. Legrand and S. Preunkert for many helpful discussions and lab assistance. We are also grateful to B. Jourdain and LGGE colleagues for field support at Col du Dôme, V. Mikhalenko and S. Kutuzov for providing Elbrus firn samples, and colleagues from EvK2 (CNR) for collection of the Himalayan snow samples.

Edited by: P. Herckes

\section{References}

Aamaas, B., Bøggild, C. E., Stordal, F., Berntsen, T., Holmén, K. I. M., and Ström, J.: Elemental carbon deposition to Svalbard snow from Norwegian settlements and long-range transport, Tellus B, 63, 340-351, doi:10.1111/j.1600-0889.2011.00531.x, 2011.

Bisiaux, M. M., Edwards, R., McConnell, J. R., Albert, M. R., Anschütz, H., Neumann, T. A., Isaksson, E., and Penner, J. E.: Variability of black carbon deposition to the East Antarctic Plateau, 1800-2000 AD, Atmos. Chem. Phys., 12, 3799-3808, doi:10.5194/acp-12-3799-2012, 2012a.

Bisiaux, M. M., Edwards, R., McConnell, J. R., Curran, M. A. J., Van Ommen, T. D., Smith, A. M., Neumann, T. A., Pasteris, D. R., Penner, J. E., and Taylor, K.: Changes in black carbon deposition to Antarctica from two high-resolution ice core records, 1850-2000 AD, Atmos. Chem. Phys., 12, 4107-4115, doi:10.5194/acp-12-4107-2012, 2012b.

Bonasoni, P., Laj, P., Marinoni, A., Sprenger, M., Angelini, F., Arduini, J., Bonafè, U., Calzolari, F., Colombo, T., Decesari, S., Di Biagio, C., di Sarra, A. G., Evangelisti, F., Duchi, R., Facchini, MC., Fuzzi, S., Gobbi, G. P., Maione, M., Panday, A., Roccato, F., Sellegri, K., Venzac, H., Verza, GP., Villani, P., Vuillermoz, E., and Cristofanelli, P.: Atmospheric Brown Clouds in the Himalayas: first two years of continuous observations at the Nepal Climate Observatory-Pyramid (5079 m), Atmos. Chem. Phys., 10, 7515-7531, doi:10.5194/acp-10-7515-2010, 2010.

Bond, T. C., Doherty, S. J., Fahey, D. W., Forster, P. M., Berntsen, T., DeAngelo, B. J., Flanner, M. G., Ghan, S., Kärcher, B., Koch, D., Kinne, S., Kondo, Y., Quinn, P. K., Sarofim, M. C., Schultz, M. G., Schulz, M., Venkataraman, C., Zhang, H., Zhang, S., Bellouin, N., Guttikunda, S. K., Hopke, P. K., Jacobson, M. Z., Kaiser, J. W., Klimont, Z., Lohmann, U., Schwarz, J. P., Shindell, D., Storelvmo, T., Warren, S. G., and Zender, C. S.: Bounding the role of black carbon in the climate system: A scientific assessment, J. Geophys. Res. Atmos., 118, 5380-5552, doi:10.1002/jgrd.50171, 2013.

Cavalli, F., Viana, M., Yttri, K. E., Genberg, J., and Putaud, J.-P.: Toward a standardised thermal-optical protocol for measuring atmospheric organic and elemental carbon: the EUSAAR protocol, Atmos. Meas. Tech., 3, 79-89, doi:10.5194/amt-3-79-2010, 2010.

Chow, J. C., Watson, J. G., Crow, D., Lowenthal, D. H., and Merrifield, T.: Comparison of IMPROVE and NIOSH 
carbon measurements, Aerosol Sci. Technol., 34, 23-34, doi:10.1080/02786820119073, 2001.

Chow, J. C., Watson, J. G., Doraiswamy, P., Chen, L.-W. A., Sodeman, D. A., Lowenthal, D. H., Park, K., Arnott, W. P., and Motallebi, N.: Aerosol light absorption, black carbon, and elemental carbon at the Fresno Supersite, California, Atmos. Res., 93, 874887, doi:10.1016/j.atmosres.2009.04.010, 2009.

Clarke, A. D. and Noone, K. J.: Soot in the Arctic snowpack: a cause for perturbations in radiative transfer, Atmos. Environ., 19, 2045-2053, doi:10.1016/0004-6981(85)90113-1, 1985.

Clarke, A. D., McNaughton, C., Kapustin, V., Shinozuka, Y., Howell, S., Dibb, J., Zhou, J., Anderson, B., Brekhovskikh, V., Turner, H., and Pinkerton, M.: Biomass burning and pollution aerosol over North America: Organic components and their influence on spectral optical properties and humidification response, J. Geophys. Res., 112, D12S18, doi:10.1029/2006JD007777, 2007.

Countess, R. J.: Interlaboratory Analyses of Carbonaceous Aerosol Samples, Aerosol Sci. Technol., 12, 114-121, doi:10.1080/02786829008959331, 1990.

Cross, E. S., Onasch, T. B., Ahern, A., Wrobel, W., Slowik, J. G., Olfert, J., Lack, D. a., Massoli, P., Cappa, C. D., Schwarz, J. P., Spackman, J. R., Fahey, D. W., Sedlacek, A., Trimborn, A., Jayne, J. T., Freedman, A., Williams, L. R., Ng, N. L., Mazzoleni, C., Dubey, M., Brem, B., Kok, G., Subramanian, R., Freitag, S., Clarke, A., Thornhill, D., Marr, L. C., Kolb, C. E., Worsnop, D. R., and Davidovits, P.: Soot Particle Studies - Instrument InterComparison - Project Overview, Aerosol Sci. Technol., 44, 592611, doi:10.1080/02786826.2010.482113, 2010.

Decesari, S., Facchini, M. C., Carbone, C., Giulianelli, L., Rinaldi, M., Finessi, E., Fuzzi, S., Marinoni, A., Cristofanelli, P., Duchi, R., Bonasoni, P., Vuillermoz, E., Cozic, J., Jaffrezo, J. L., and Laj, P.: Chemical composition of $\mathrm{PM}_{10}$ and $\mathrm{PM}_{1}$ at the highaltitude Himalayan station Nepal Climate Observatory-Pyramid (NCO-P) (5079 m a.s.1.), Atmos. Chem. Phys., 10, 4583-4596, doi:10.5194/acp-10-4583-2010, 2010.

Doherty, S. J., Warren, S. G., Grenfell, T. C., Clarke, A. D., and Brandt, R. E.: Light-absorbing impurities in Arctic snow, Atmos. Chem. Phys., 10, 11647-11680, doi:10.5194/acp-1011647-2010, 2010.

Dominé, F., Lauzier, T., Cabanes, A., Legagneux, L., Kuhs, W. F., Techmer, K., and Heinrichs, T.: Snow metamorphism as revealed by scanning electron microscopy., Microsc. Res. Tech., 62, 3348, doi:10.1002/jemt.10384, 2003.

Ducret, J. and Cachier, H.: Particulate carbon content in rain at various temperate and tropical locations, J. Atmos. Chem., 15, 5567, doi:10.1007/BF00053609, 1992.

Facchini, M. C., Decesari, S., Mircea, M., Fuzzi, S., and Loglio, G.: Surface tension of atmospheric wet aerosol and cloud/fog droplets in relation to their organic carbon content and chemical composition, Atmos. Environ., 34, 4853-4857, 2000.

Flanner, M. G., Zender, C. S., Randerson, J. T., and Rasch, P. J.: Present-day climate forcing and response from black carbon in snow, J. Geophys. Res., 112, D11202 doi:10.1029/2006jd008003, 2007.

Flanner, M. G., Liu, X., Zhou, C., Penner, J. E., and Jiao, C.: Enhanced solar energy absorption by internally-mixed black carbon in snow grains, Atmos. Chem. Phys., 12, 4699-4721, doi:10.5194/acp-12-4699-2012, 2012.
Ginot, P., Dumont, M., Lim, S., Patris, N., Taupin, J.-D., Wagnon, P., Gilbert, A., Arnaud, Y., Marinoni, A., Bonasoni, P., and Laj, P.: A 10 year record of black carbon and dust from a Mera Peak ice core (Nepal): variability and potential impact on melting of Himalayan glaciers, The Cryosphere, 8, 1479-1496, doi:10.5194/tc-8-1479-2014, 2014.

Guilhermet, J., Preunkert, S., Voisin, D., Baduel, C., and Legrand, M.: Major 20th century changes of water-soluble humic-like substances (HULIS WS ) aerosol over Europe inferred from Alpine ice cores, J. Geophys. Res. Atmos., 118, 3869-3878, doi:10.1002/jgrd.50201, 2013.

Gysel, M., Laborde, M., Olfert, J. S., Subramanian, R., and Gröhn, A. J.: Effective density of Aquadag and fullerene soot black carbon reference materials used for SP2 calibration, Atmos. Meas. Tech., 4, 2851-2858, doi:10.5194/amt-4-2851-2011, 2011.

Hadley, O. L., Corrigan, C. E., and Kirchstetter, T. W.: Modified Thermal-Optical Analysis Using Spectral Absorption Selectivity To Distinguish Black Carbon from Pyrolized Organic Carbon, Environ. Sci. Technol., 42, 8459-8464, doi:10.1021/es800448n, 2008.

Hagler, G. S. W., Bergin, M. H., Smith, E. A., Dibb, J. E., Anderson, C., and Steig, E. J.: Particulate and water-soluble carbon measured in recent snow at Summit, Greenland, Geophys. Res. Lett., 34, L16505, doi:10.1029/2007GL030110, 2007.

Hansen, J. and Nazarenko, L.: Soot climate forcing via snow and ice albedos, Proc. Natl. Acad. Sci. USA, 101, 423-428, doi:10.1073/pnas.2237157100, 2004.

Jacobson, M. Z.: Strong radiative heating due to the mixing state of black carbon in atmospheric aerosols., Nature, 409, 695-697, doi:10.1038/35055518, 2001.

Jenk, T. M., Szidat, S., Schwikowski, M., Gäggeler, H. W., Brütsch, S., Wacker, L., Synal, H.-A., and Saurer, M.: Radiocarbon analysis in an Alpine ice core: record of anthropogenic and biogenic contributions to carbonaceous aerosols in the past (1650-1940), Atmos. Chem. Phys., 6, 5381-5390, doi:10.5194/acp-6-53812006, 2006.

Jenkins, M., Kaspari, S., Kang, S., Grigholm, B., and Mayewski, P. A.: Black carbon concentrations from a Tibetan Plateau ice core spanning 1843-1982: recent increases due to emissions and glacier melt, The Cryosphere Discuss., 7, 4855-4880, doi:10.5194/tcd-7-4855-2013, 2013.

Jeong, C.-H., Hopke, P. K., Kim, E., and Lee, D.-W.: The comparison between thermal-optical transmittance elemental carbon and Aethalometer black carbon measured at multiple monitoring sites, Atmos. Environ., 38, 5193-5204, 2004.

Karanasiou, A., Diapouli, E., Cavalli, F., Eleftheriadis, K., Viana, M., Alastuey, A., Querol, X., and Reche, C.: On the quantification of atmospheric carbonate carbon by thermal/optical analysis protocols, Atmos. Meas. Tech., 4, 2409-2419, doi:10.5194/amt4-2409-2011, 2011.

Kaspari, S. D., Schwikowski, M., Gysel, M., Flanner, M. G., Kang, S., Hou, S., and Mayewski, P. A.: Recent increase in black carbon concentrations from a Mt. Everest ice core spanning 1860-2000 AD, Geophys. Res. Lett., 38, L04703, doi:10.1029/2010g1046096, 2011.

Kondo, Y., Sahu, L., Moteki, N., Khan, F., Takegawa, N., Liu, X., Koike, M., and Miyakawa, T.: Consistency and Traceability of Black Carbon Measurements Made by Laser-Induced Incandescence, Thermal-Optical Transmittance, and Filter-Based 
Photo-Absorption Techniques, Aerosol Sci. Technol., 45, 295312, doi:10.1080/02786826.2010.533215, 2011.

Laborde, M., Mertes, P., Zieger, P., Dommen, J., Baltensperger, U., and Gysel, M.: Sensitivity of the Single Particle Soot Photometer to different black carbon types, Atmos. Meas. Tech., 5, 10311043, doi:10.5194/amt-5-1031-2012, 2012a.

Laborde, M., Schnaiter, M., Linke, C., Saathoff, H., Naumann, K.H., Möhler, O., Berlenz, S., Wagner, U., Taylor, J. W., Liu, D., Flynn, M., Allan, J. D., Coe, H., Heimerl, K., Dahlkötter, F., Weinzierl, B., Wollny, A. G., Zanatta, M., Cozic, J., Laj, P., Hitzenberger, R., Schwarz, J. P., and Gysel, M.: Single Particle Soot Photometer intercomparison at the AIDA chamber, Atmos. Meas. Tech., 5, 3077-3097, doi:10.5194/amt-5-3077-2012, 2012b.

Lack, D. A., Moosmüller, H., McMeeking, G. R., Chakrabarty, R. K., and Baumgardner, D.: Characterizing elemental, equivalent black, and refractory black carbon aerosol particles: a review of techniques, their limitations and uncertainties., Anal. Bioanal. Chem., 406, 99-122, doi:10.1007/s00216-013-7402-3, 2014.

Lavanchy, V. M. H., Gäggeler, H. W., Schotterer, U., Schwikowski, M., and Baltensperger, U.: Historical record of carbonaceous particle concentrations from a European high-alpine glacier (Colle Gnifetti, Switzerland), J. Geophys. Res. Atmos., 104, $21227-$ 21236, doi:10.1029/1999jd900408, 1999.

Legrand, M., Preunkert, S., Schock, M., Cerqueira, M., KasperGiebl, A., Afonso, J., Pio, C., Gelencsér, A., and DombrowskiEtchevers, I.: Major 20th century changes of carbonaceous aerosol components (EC, WinOC, DOC, HULIS, carboxylic acids, and cellulose) derived from Alpine ice cores, J. Geophys. Res., 112, D23S11, doi:10.1029/2006jd008080, 2007.

Maupetit, F. and Delmas, R. J.: Snow chemistry of high altitude glaciers in the French Alps, Tellus B, 46, 304-324, doi:10.3402/tellusb.v46i4.15806, 1994.

McConnell, J. R., Edwards, R., Kok, G. L., Flanner, M. G., Zender, C. S., Saltzman, E. S., Banta, J. R., Pasteris, D. R., Carter, M. M., and Kahl, J. D. W.: 20th-century industrial black carbon emissions altered arctic climate forcing, Science, 317, 1381-1384, doi:10.1126/science.1144856, 2007.

Ming, J., Cachier, H., Xiao, C., Qin, D., Kang, S., Hou, S., and $\mathrm{Xu}$, J.: Black carbon record based on a shallow Himalayan ice core and its climatic implications, Atmos. Chem. Phys., 8, 13431352, doi:10.5194/acp-8-1343-2008, 2008.

Ming, J., Xiao, C., Cachier, H., Qin, D., Qin, X., Li, Z., and Pu, J.: Black Carbon (BC) in the snow of glaciers in west China and its potential effects on albedos, Atmos. Res., 92, 114-123, doi:10.1016/j.atmosres.2008.09.007, 2009.

Miyazaki, Y., Kondo, Y., Han, S., Koike, M., Kodama, D., Komazaki, Y., Tanimoto, H., and Matsueda, H.: Chemical characteristics of water-soluble organic carbon in the Asian outflow, J. Geophys. Res., 112, D22S30, doi:10.1029/2007JD009116, 2007.

Moteki, N. and Kondo, Y.: Dependence of Laser-Induced Incandescence on Physical Properties of Black Carbon Aerosols: Measurements and Theoretical Interpretation, Aerosol Sci. Technol., 44, 663-675, doi:10.1080/02786826.2010.484450, 2010.

Ohata, S., Moteki, N., and Kondo, Y.: Evaluation of a Method for Measurement of the Concentration and Size Distribution of Black Carbon Particles Suspended in Rainwater, Aerosol Sci. Technol., 45, 1326-1336, doi:10.1080/02786826.2011.593590, 2011.
Ohata, S., Moteki, N., Schwarz, J., Fahey, D., and Kondo, Y.: Evaluation of a Method to Measure Black Carbon Particles Suspended in Rainwater and Snow Samples, Aerosol Sci. Technol., 47, 1073-1082, doi:10.1080/02786826.2013.824067, 2013.

Painter, T. H., Flanner, M. G., Kaser, G., Marzeion, B., VanCuren, R. A., and Abdalati, W.: End of the Little Ice Age in the Alps forced by industrial black carbon, Proc. Natl. Acad. Sci., 110, 15216-15221, doi:10.1073/pnas.1302570110, 2013.

Petzold, A., Ogren, J. A., Fiebig, M., Laj, P., Li, S.-M., Baltensperger, U., Holzer-Popp, T., Kinne, S., Pappalardo, G., Sugimoto, N., Wehrli, C., Wiedensohler, A., and Zhang, X.-Y.: Recommendations for reporting "black carbon" measurements, Atmos. Chem. Phys., 13, 8365-8379, doi:10.5194/acp-13-83652013, 2013.

Preunkert, S., Wagenbach, D., Legrand, M., and Vincent, C.: Col du Dôme (Mt Blanc Massif, French Alps) suitability for ice-core studies in relation with past atmospheric chemistry over Europe, Tellus B, 52, 993-1012, doi:10.1034/j.1600-0889.2000.d01-8.x, 2000 .

Savarino, J. and Legrand, M.: High northern latitude forest fires and vegetation emissions over the last millennium inferred from the chemistry of a central Greenaldn ice core, 103 (July 1989), 82678279, 1998.

Schmid, H., Laskus, L., Jürgen, Abraham, H., Baltensperger, U., Lavanchy, V., Bizjak, M., Burba, P., Cachier, H., Crow, D., Chow, J., Gnauk, T., Even, A., ten Brink, H. M., Giesen, K.P., Hitzenberger, R., Hueglin, C., Maenhaut, W., Pio, C., Carvalho, A., Putaud, J.-P., Toom-Sauntry, D. and Puxbaum, H.: Results of the "carbon conference" international aerosol carbon round robin test stage I, Atmos. Environ., 35, 2111-2121, doi:10.1016/S1352-2310(00)00493-3, 2001.

Schwarz, J. P., Gao, R. S., Fahey, D. W., Thomson, D. S., Watts, L. a., Wilson, J. C., Reeves, J. M., Darbeheshti, M., Baumgardner, D. G., Kok, G. L., Chung, S. H., Schulz, M., Hendricks, J., Lauer, A., Kärcher, B., Slowik, J. G., Rosenlof, K. H., Thompson, T. L., Langford, A. O., Loewenstein, M. and Aikin, K. C.: Single-particle measurements of midlatitude black carbon and light-scattering aerosols from the boundary layer to the lower stratosphere, J. Geophys. Res., 111, D16207, doi:10.1029/2006JD007076, 2006.

Schwarz, J. P., Doherty, S. J., Li, F., Ruggiero, S. T., Tanner, C. E., Perring, A. E., Gao, R. S., and Fahey, D. W.: Assessing Single Particle Soot Photometer and Integrating Sphere/Integrating Sandwich Spectrophotometer measurement techniques for quantifying black carbon concentration in snow, Atmos. Meas. Tech., 5, 2581-2592, doi:10.5194/amt-5-2581-2012, 2012.

Slowik, J. G., Cross, E. S., Han, J.-H., Davidovits, P., Onasch, T. B., Jayne, J. T., Williams, L. R., Canagaratna, M. R., Worsnop, D. R., Chakrabarty, R. K., Moosmüller, H., Arnott, W. P., Schwarz, J. P., Gao, R.-S., Fahey, D. W., Kok, G. L., and Petzold, A.: An Inter-Comparison of Instruments Measuring Black Carbon Content of Soot Particles, Aerosol Sci. Technol., 41, 295-314, doi:10.1080/02786820701197078, 2007.

Sterle, K. M., McConnell, J. R., Dozier, J., Edwards, R., and Flanner, M. G.: Retention and radiative forcing of black carbon in eastern Sierra Nevada snow, The Cryosphere, 7, 365-374, doi:10.5194/tc-7-365-2013, 2013. 
Stephens, M., Turner, N., and Sandberg, J.: Particle identification by laser-induced incandescence in a solid-state laser cavity., Appl. Opt., 42, 3726-3736, 2003.

Ten Brink, H., Maenhaut, W., Hitzenberger, R., Gnauk, T., Spindler, G., Even, A., Chi, X., Bauer, H., Puxbaum, H., Putaud, J.-P., Tursic, J., and Berner, A.: INTERCOMP2000: the comparability of methods in use in Europe for measuring the carbon content of aerosol, Atmos. Environ., 38, 6507-6519, 2004.

Thevenon, F., Anselmetti, F. S., Bernasconi, S. M., and Schwikowski, M.: Mineral dust and elemental black carbon records from an Alpine ice core (Colle Gnifetti glacier) over the last millennium, J. Geophys. Res., 114, D17102, doi:10.1029/2008jd011490, 2009.

Torres, A., Bond, T. C., Lehmann, C. M. B., Subramanian, R., and Hadley, O. L.: Measuring Organic Carbon and Black Carbon in Rainwater: Evaluation of Methods, Aerosol Sci. Technol., 48, 239-250, doi:10.1080/02786826.2013.868596, 2014.

Viana, M., Maenhaut, W., ten Brink, H. M., Chi, X., Weijers, E., Querol, X., Alastuey, A., Mikuška, P., and Večeřa, Z.: Comparative analysis of organic and elemental carbon concentrations in carbonaceous aerosols in three European cities, Atmos. Environ., 41, 5972-5983, 2007.

Wang, M., Xu, B., Zhao, H., Cao, J., Joswiak, D., Wu, G., and Lin, S.: The Influence of Dust on Quantitative Measurements of Black Carbon in Ice and Snow when Using a Thermal Optical Method, Aerosol Sci. Technol., 46, 60-69, doi:10.1080/02786826.2011.605815, 2012.
Warren, S. G.: Impurities in Snow - Effects on Albedo and Snowmelt Review, Ann. Glaciol., 5, 177-179, 1984.

Wendl, I. A., Menking, J. A., Färber, R., Gysel, M., Kaspari, S. D., Laborde, M. J. G., and Schwikowski, M.: Optimized method for black carbon analysis in ice and snow using the Single Particle Soot Photometer, Atmos. Meas. Tech., 7, 2667-2681, doi:10.5194/amt-7-2667-2014, 2014.

Xu, B., Cao, J., Hansen, J., Yao, T., Joswia, D. R., Wang, N., Wu, G., Wang, M., Zhao, H., Yang, W., Liu, X., and He, J.: Black soot and the survival of Tibetan glaciers, Proc. Natl. Acad. Sci., 106, 22114-22118, doi:10.1073/pnas.0910444106, 2009.

Yang, L., Xiaoye, Z., Sunling, G., Huizheng, C., Dan, W., Wenjun, Q., and Junying, S.: Comparison of EC and BC and evaluation of dust aerosol contribution to light absorption in Xi' an, China., Environ. Monit. Assess., 120, 301-12, doi:10.1007/s10661-0059062-z, 2006.

Yu, J. Z., Yang, H., Zhang, H., and Lau, A. K. H.: Size distributions of water-soluble organic carbon in ambient aerosols and its size-resolved thermal characteristics, Atmos. Environ., 38, 1061-1071, 2004.

Zanatta, M.: Dvelopment of a methodology for deriving black carbon in snow samples: application to Himalayan samples, Master Thesis, University of Pavia., 2012. 